Review

\title{
Microwave-Sensitive Reactors to the Rescue: From Microwave-Assisted Chemistry to Environmental Applications
}

\author{
${ }^{1,2}$ Gjergji Shore, ${ }^{1}$ Dhimitri Gusho, ${ }^{1}$ Hassan Hassan and ${ }^{1}$ Eugenia Gjuraj \\ ${ }^{1}$ Humber School of Applied Technology, 205 Humber College Blvd, Etobicoke, Ontario, Canada \\ ${ }^{2}$ Mikroen Solutions Inc, Mississauga, Ontario, Canada
}

Article history

Received: 15-01-2018

Revised: 23-04-2018

Accepted: 22-05-2018

Corresponding Author: Gjergji Shore

Humber School of Applied

Technology, 205 Humber

College Blvd, Etobicoke,

Ontario, Canada

Email: Gjergji.Shore@humber.ca

\section{Introduction}

\section{Reactors Used in Flow Microprocesses}

In particular, continuous flow systems based on microfluidic technology, known as microreactors, are becoming commonly employed in organic synthesis, both on the research scale and process development (Kirschning et al., 2006; Seeberger et al., 2007; Jas and Kirschning, 2003).

Continuous flow systems do offer several advantages when compared to batch based protocols, such as:

Process Reproducibility and Reliability (Jas and Kirschning, 2003; Geyer et al., 2006)

Flow processes are characterized by constant mixture composition; also, the accumulation of unreacted reagents is avoided due to their fast removal from the reaction zone. Because of the small cross-sectional dimensions of the reactor, the heat and mass transfer efficiency is increased and the effects of erratic mixing and thermal gradients are largely avoided (Garcia-Edigo et al., 2003).

\section{Facile Automation}

Not only are considerable amounts of time, materials and human labour involved in identifying the optimal reaction conditions for batch reactions on a small scale, oftentimes these conditions cannot be readily transferred to a scaled-up process. The small dimensions of microstructured continuous flow systems, on the other hand, allow for the use of minimal amounts of reagents and make possible the rapid screening of reaction conditions. The automation of such systems ensures tighter quality control, by allowing immediate information feedback from the in-line analytical modules and the rapid application of this feedback in order to optimize reaction conditions (Fletcher et al., 2002a).

\section{Increased Process Safety}

In general, process automation in these devices requires very little human intervention and this manner of conducting potentially explosive reactions greatly improves safety for individuals. 


\section{Process Diversification}

Linear, divergent, as well as convergent multistep syntheses are also feasible by assembling a series of flow reactors, provided that solvent switching is not required and that full conversion of starting materials in each step is ensured (Colombo and Peretto, 2008).

These positive features of flowed synthesis can be utilized successfully by synthetic chemists in order to overcome the hurdles associated with the optimization of chemical transformations conducted in roundbottomed flasks. Furthermore, in order to obtain significant amounts of product, the reactors are simply run longer (the scale-out principle) (Thayer, 2005) or alternatively, several reactors can be placed in parallel (numbering-up) (Jas and Kirschning, 2003) all using identical reaction conditions (Fletcher et al., 2002a; DeWitt, 1999).

In addition to the advantages stated above, the use of microfluidic continuous flow technology brings with it several unique features from an engineering standpoint that significantly enhance the application of such systems.

\section{Diffusion-Controlled Mass Transfer}

It is known that the flow regime in microchannels is laminar, the typical Reynolds number representing the ratio of inertia forces to viscous forces is below 10 , as compared to a Reynolds number greater than 3000 typically associated with turbulent flow in channels. Under laminar flow conditions, the mass transfer across a channel section will be dominated by diffusion, which allows for relatively accurate predictions of the flow behaviour, leading in turn to a highly controlled manipulation of the flow regime within a microfluidic channel network (Fletcher et al., 2002a). This feature of the flow systems enables the operator to accurately control the reaction progress by initiating or quenching reactions in a controlled manner (Seeberger et al., 2007; Fletcher et al., 2002a).

A close estimate of the time $t$ needed for diffusion across the entire width of the channel $w$ is calculated based on Fick's law (Fick, 1855), $t=5 w^{2} / D$ ( $D$ is the diffusion coefficient).

It is clear that by scaling down the dimensions of the channel there is going to be a significant reduction in time needed for complete diffusion-based mixing. However, even for microchannel-based systems, the time needed for the complete mixing of two streams can be high (for a typical channel width of $100 \mu \mathrm{m}$ and an average value of $D$ of $5 \times 10^{-10} \mathrm{~m}^{2} \mathrm{~s}^{-1}$ the time is about 100s). Considering the small dimensions of microreactors, the incomplete mixing of reagent streams can lead to poor reactivity (Fletcher et al., 2002a).

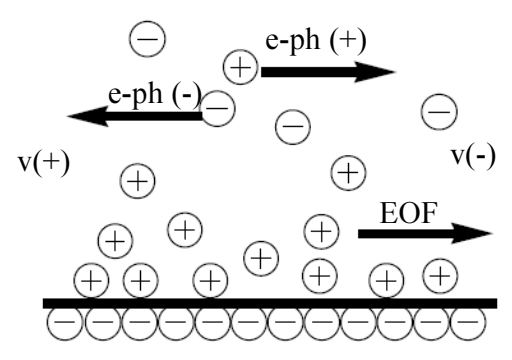

Fig. 1: Voltage-driven mobility of different charged species and EOF generated by the diffuse layer of cations adsorbed on the negatively charged glass wall

\section{High Surface Area-to-Volume Ratio}

Scaling-down of reactor size increases the surface area-to-volume ratio considerably (for example, the surface area-to-volume ratio of a tubular channel follows a $2 r: r^{2}$ relationship, where $r$ is the radius) to the extent that it plays an active role by influencing several parameters of the process.

\section{Electro-Osmotic Flow (EOF)}

EOF is one of the main surface-dependent applications in these reactors (due to the high surface-tovolume ratio). The operating principle of EOF is shown in Fig. 1. The negative charge of the glass channel wall (created through ionization of immobile surface groups) attracts a nanometers-thick layer of counter-ions, which, under the influence of an electrical field applied along the channel, moves at a constant speed towards the negative electrode, thus dragging the solution in the channel along (Fletcher et al., 2002a).

In addition to EOF, the charged species within the electric field also have an additional electrophoretic velocity (e-ph vector), with a magnitude comparable to EOF velocity (Hunter, 1981). This application, although limited to glass and high polarity solvents, has several advantages over alternative pumping methods: It can be miniaturized easily as there are no mechanical parts involved and the voltage sequence can be applied under automated computer control (Fletcher et al., 2002b). This feature of using voltage sequences to direct reagents to selected points at specified times, provides the ability to control the spatial and temporal evolution of chemical processes (Fletcher et al., 2002a; 2002b).

\section{Surface Functionalization}

The relatively large surface area of microstructured channels can be utilized in several ways: (a) The surface can be modified with specific chemical groups (such as amines) that can bind biologically active molecules, such as antibodies. This bio-functionalized surface can be a rapid, flexible tool for bioanalysis (Lagally and Mathies, 2004). (b) The electrical charge of the surface can be altered by either plasma treatment ( $\mathrm{Hu}$ et al., 2002) or 
surface coating with silanising agents (Handique et al., 2000). The charge alteration can in turn alter the EOF direction within the channel. Loading the channel surface with different charges can result in counter-flows within the same channel, which can improve mixing significantly (Hau et al., 2013). (c) The surface can be coated with either hydrophilic or hydrophobic groups (usually by treating the surface with silanising reagents), in order to change the contact behaviour of reagents with the surface (Handique et al., 2000).

\section{Heat and Mass Transfer}

The heat and mass transfer in channels with a high surface-to-volume ratio is significantly improved due to a significantly higher heat and mass transfer area per unit volume (Seeberger et al., 2007). Furthermore, the heat and mass transfer within a small volume occurs in a shorter time, enabling the quick formation of a homogeneous reaction medium, a factor that will have a positive impact on reaction kinetics and conversion rates. As a specific example, highly exothermic reactions are safely handled in these systems due to relatively small thermal mass and rapid heat dissipation.

\section{In-Line Integration of Chemical Analysis and Automated Processing Equipment}

The capability to integrate in-line analytical and processing equipment with microreactors for rapid monitoring of reaction conditions is considered a very important feature of such reactors. Using these capabilities, assessing chemical kinetics and identifying optimal conditions of multistep processes is possible in a controlled fashion (Zhang et al., 2006).

As an added benefit, feedback-controlled optimization of reaction conditions with automated methodology can greatly reduce the time and labour costs associated with development of synthetic protocols (Fletcher et al., 2002b). The availability of UV and FTIR detectors has made possible the integration of spectroscopic measurements in microreactors (Lobbecke et al., 2005), although the FTIR spectrometers can only be used with silicon reactors which are IR transparent (Floyd et al., 2005). Raman spectroscopy has been incorporated also into the microreactor design as an effective monitoring device (Lobbecke et al., 2005). A recent report describes the successful use of NMR spectroscopy to assess the reaction progress during catalytic hydrogenation in microreactors (Bouchard et al., 2008).

In a typical example, reagents are injected into a lead discovery and optimization system by the pumping array. When the reagents reach the microreactor they mix and react. The reaction time depends on the combination of flow rate and channel size and length. After exiting the reactor, the product slug is detected by an UV-Visible detector. The detection of the slug triggers an injection of part of the slug into the HPLC system, where reaction components are time-resolved. Then, the appearance of a product with appropriate properties, as identified by a mass spectrometer, triggers an entry into the automated flow assay system (Wong-Hawkes et al., 2007). Such multiple modules within one microreactor design can clearly make these systems attractive tools for the pharmaceutical industry, where high throughput and information-rich techniques are constantly being sought for the rapid evaluation of reaction arrays (Seeberger et al., 2007).

From an engineering viewpoint, flow microreactors are continuous flow devices with built-in fluid channels, whose Internal Diameters (ID) range from fractions of a millimeter up to several millimeters (Fig. 2). The basic reactor design includes an inlet, mixing and reaction and an outlet. A more advanced design can include built-in chemical or physical sensors and additional sections for concentrating and capturing reagents (Lobbecke et al., 2005; De Mas et al., 2005).

Stainless steel is a popular material for these reactors, due to its robustness and availability. The configuration can be modified easily, due to the wide availability of micromixers and heat exchangers that can easily fit into such systems. These reactors are compatible with organic solvents and can be operated under elevated temperature and pressure conditions; however, they are not compatible with reactions involving corrosive agents such as strong acids or bases (Pennemann et al., 2004).

Although polymer-based microreactors are easy to manufacture and relatively inexpensive, they show low thermal conductivity and can be affected adversely by reactions involving organic solvents that can dissolve the polymeric material or cause swelling (Lee et al., 2003), thus the application of these reactors is restricted to ambient temperature aqueous chemistry and biochemical processes (Hansen et al., 2006; Wang et al., 2006). Ceramic-based microreactors are stable at high temperatures and chemically inert, but their manufacturing process is complicated by the thermal expansion/shrinkage of ceramic materials during baking (Knitter et al., 2001). Glass, is also a popular choice as a material for microreactors, since fabrication methods are well-established; glass is chemically inert and enables the use of visible light detection, however, creating three-dimensional channels in glass is a difficult and costly process (Fletcher et al., 2002a; Kikutani et al., 2002). Silicon is receiving wide attention as a material with high mechanical strength and good chemical compatibility. Well-established wet and dry etching techniques enable the controlled creation of microchannels. Also, the oxidation of silicon surface forms a glass layer, making silicon chips functionally equivalent to glass reactors (Madou, 2002; Wada et al., 2006). A protective coating process, such as $\mathrm{Ni}$ electroplating, can be applied to silicon surfaces in order to increase the chemical resistance of such reactors (De Mas et al., 2003). 


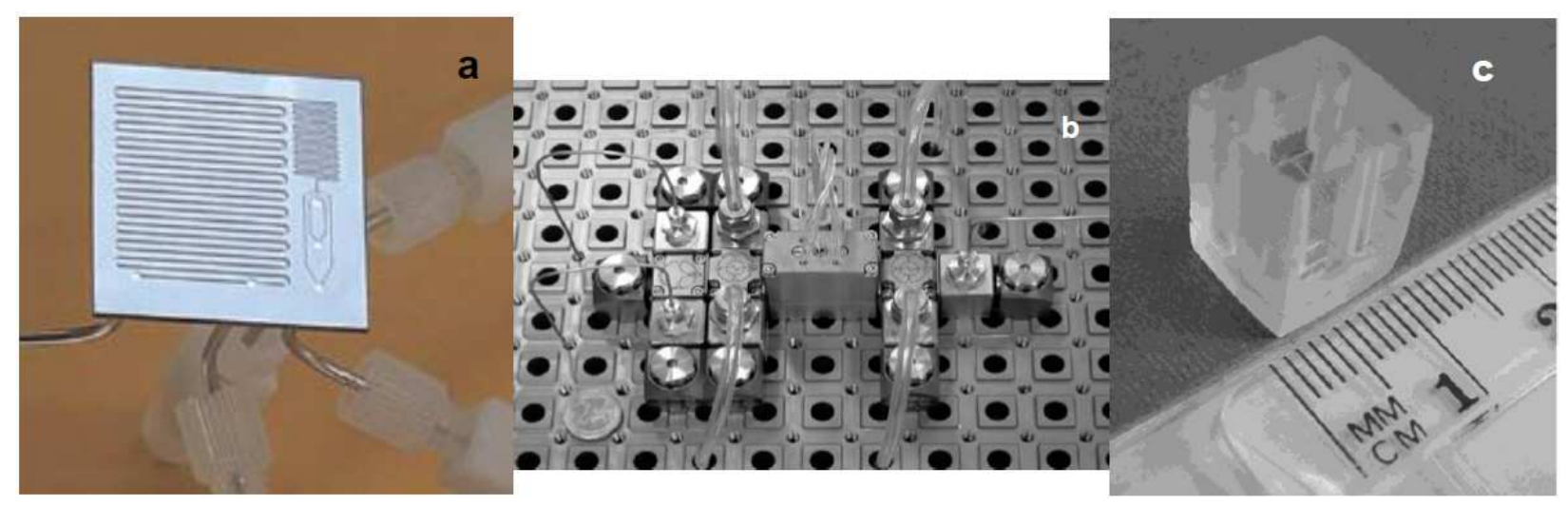

Fig. 2: Continuous flow microreactors. (a) silicon-based Jensen microreactor (Ratner et al., 2005); (b) stainless steel microreactor system (Solodenko et al., 2004); (c) glass chip microreactor (Watts and Haswell, 2005)

\section{Synthetic Applications Using Flow Microreactors}

The majority of reactions conducted in continuous flow microstructured reactors involve homogeneous liquid solutions, as the design of such devices is best suited for handling liquids. However, recent examples have shown that multiphase reactions can be conducted successfully in flow as well.

\section{Liquid Phase Reactions}

A wide range of liquid-phase reactions have been performed in microreactor devices, including epoxidations (Snyder et al., 2005), aldol reactions (Wiles et al., 2001a), cross coupling reactions (Snyder et al., 2005; Solodenko et al., 2004), multicomponent reactions (Acke et al., 2006), nitrations (Panke et al., 2003), glycosylations (Snyder et al., 2005), olefinations (Snyder et al., 2005; Skelton et al., 2001), peptide couplings (Wiles et al., 2001b), Grignard reactions (Taghavi-Moghadam et al., 2008) and Swern oxidations (Kawaguchi et al., 2005) to name a few. Liquid-phase reactions carried out in flow format benefit from the efficient mass and heat transfer inside microreactors and also from the fact that only small amounts of reactants are in the system at any given time.

An example of a glycosylation reaction is shown in Scheme 1 where more than 40 reactions for a coupling between mannoside $\mathbf{1}$ and galactoside $\mathbf{2}$ performed in a Jensen microreactor system (Fig. 4a) were observed within a day, using as little as $2.0 \mathrm{mg}$ of glycosylating reagent for each reaction. A conventional batch procedure for the same protocol required significantly larger quantities of starting materials and was limited to three reactions per day (Ratner et al., 2005).

\section{Liquid-Solid Reactions}

Chemical processes that require solid reactants that do not dissolve are difficult to carry out in microreactors, since solids may clog the channel network. Several different approaches have been used in order to carry out reactions that use solid catalysts. Catalytically-active metals may be immobilized on the inner walls of a reactor or may be placed on miniaturized poles in the reactor channels (Jensen, 2001). Another approach is to load the catalyst on polymer beads in pre-packed reaction cartridges that are placed in the reactor channel (Snyder et al., 2005; Saaby et al., 2005). In these processes, effective interaction between the phases take place due to a high surface to volume ratio which can lead to considerable reaction rate enhancement.

As an example, Heck reactions (Snyder et al., 2005) have been carried out in the stainless steel reactor shown in Fig. 4b; a solution of phenyl iodide 5 and ethyl acrylate $\mathbf{6}$ has been passed through a cartridge loaded with a $10 \% \mathrm{Pd}$ on charcoal (Scheme 2). The product (ethyl cinamate 7) was isolated in $95 \%$ yield after $30 \mathrm{~min}$ at $150^{\circ} \mathrm{C}$, compared to a batch strategy for the same reaction that gave $100 \%$ conversion after $10 \mathrm{~min}$ at $130^{\circ} \mathrm{C}$ using an homogeneous catalyst.

\section{Liquid-Gas Reactions}

Continuous flow microreactors are particularly suited for liquid-gas reactions, which are generally difficult to perform because of the hazardous nature of reactive gases. The high mass transfer rates promote gas-liquid reactions that are limited by the transport of gas species into the liquid reaction medium in larger vessels (Kobayashi et al., 2004). However, reactor design has to incorporate engineering features that allow for the careful control of gas flow in the reactor, as well as the regulation of contact time between gas and liquid and the separation of the gaseous phase at the end of the reaction (Jahnisch et al., 2004). The utility of microreactors for this chemistry has been illustrated for reactions such as fluorination (Jahnisch et al., 2000), chlorination (Ehrich et al., 2002), nitration4 etc. 
<smiles>N#Cc1ccc(/C=N\CCc2ccc(O)cc2)cc1</smiles>

(a)

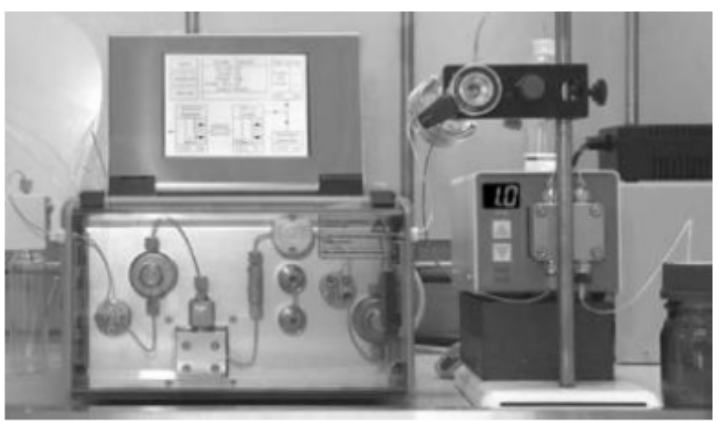

(b)

Fig. 3: (a) A chemoselective reductive amination conducted in an $\mathrm{H}-\mathrm{Cube}{ }^{\circledR}$ hydrogenation reactor; (b) H-Cube ${ }^{\circledR}$ flow hydrogenation reactor

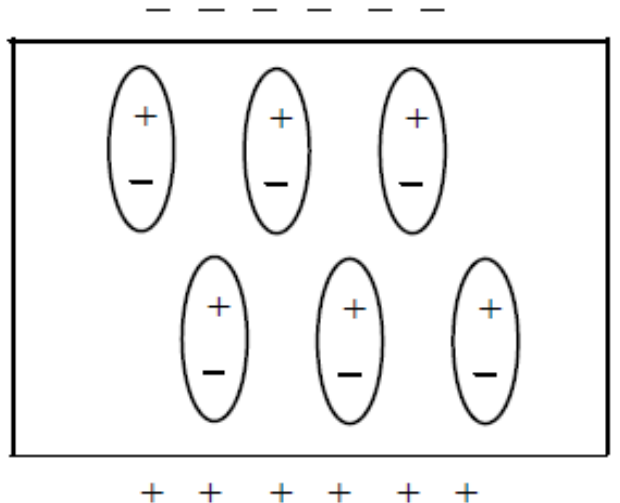

(a)

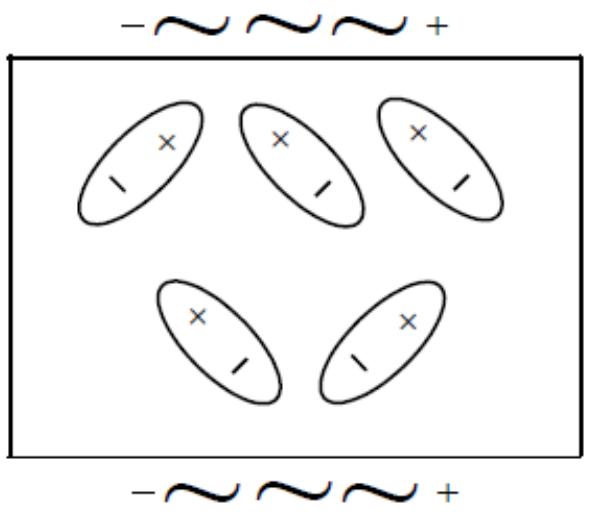

(b)

Fig. 4: Effects of surrounding electric field on dipole orientation: (a) static electric field (b) alternating electric field

As an example, the direct fluorination of toluene (Scheme 3) was performed at room temperature in a silicon microreactor that was internally coated with nickel to render it compatible with the corrosive fluorine gas (De Mas et al., 2003). Taking advantage of highly efficient heat transfer enables this exothermic reaction to be manageably conducted under flow conditions; monofluorination of toluene was achieved with very good selectivity. By using five equivalents of elemental fluorine in methanol as solvent, $96 \%$ conversion was reported, yielding the monofluorinated toluenes $\mathbf{9 , 1 0}$ and $\mathbf{1 1}$ in a ratio of $3: 1: 2$, respectively.

\section{Liquid-Gas-Solid Reactions}

Important multiphase catalytic processes, such as catalytic hydrogenation and oxidation reactions often suffer from long reaction times due to poor interactions between the different phases. Again, continuous flow microreactor technology ensures higher reaction rates due to an increased surface-to-volume ratio and allows for accurate control of crucial parameters such as temperature and residence time.

As an example, hydrogenation of imine 12 (Fig. 3a) was conducted in an $\mathrm{H}-\mathrm{Cube}^{\circledR}$, a commercially-available continuous flow hydrogenation reactor (Fig. 3b), by 
employing a catalyst cartridge loaded with $10 \%$ palladium on charcoal at 20 bar hydrogen pressure. The reaction yielded the desired amine $\mathbf{1 3}$ quantitatively and in high purity, without affecting other functional groups such as the nitrile and the phenol (Saaby et al., 2005).

\section{Natural Product Synthesis}

The technological scope of the flow microreactor approach has been tested in the synthesis of natural products. Not only has this technology been able to handle multicomponent and multistep operations in order to construct architecturally diverse natural product molecules such as grossamide (Baxendale et al., 2006a) and oxomaritidine (Baxendale et al., 2006b). The synthesis of grossamide $\mathbf{1 8}$ was eventually achieved in less than a day (Scheme 4).

\section{Limitations of Continuous Flow Reactors}

Continuous flow technology is often superior to batch processing in efficiency and practicability (Jas and Kirschning, 2003), however, a critical viewing of continuous flow systems is often necessitated by the need to define limitations of such systems. Such limitations include:

Continuous flow reactors often face cost-related issues. The fabrication of chip microreactors requires specialized facilities with fabrication costs running into the thousands of dollars.

These reactors often possess a complex engineering design that requires inclusion of complex heating and mixing modules. Although the laminar flow regime has often been considered a favorable feature due to diffusioncontrolled mass transfer (Seeberger et al., 2007), it does slow the kinetics of chemical transformations. Also, connecting microreactors to external fluid reservoirs under pressurized conditions is considered a challenging task technically due to potential leakage problems or mechanical stress on the system (Fredrickson and Fan, 2004).

In order to be fully automated the system design has to incorporate in-line facilities for purification of intermediates or final products: A solution which is both expensive and technically challenging.

Chemical transformations that require solid starting materials or yield solid intermediates and/or products are difficult to carry out, since solids can clog the channels and potentially incapacitate the entire system.
These reactors often face problems associated with different kinetics of reactions and the necessity for different solvents when performing multistep syntheses in the flow-through mode (Kirschning et al., 2006).

\section{Microwave Irradiation Theory}

Microwave irradiation is normally considered the part of the electromagnetic spectrum occurring between infrared and radiofrequency radiation; the wavelengths lie between 0.1 and $100 \mathrm{~cm}$ and the frequencies between $300 \mathrm{GHz}$ and $300 \mathrm{MHz}$. Two major applications of microwave emitting devices are telecommunications and heating. Wavelengths between $1-25 \mathrm{~cm}$ are used extensively for radar and telecommunication purposes, whereas the heating applications use Industrial, Scientific and Medical (ISM) frequencies which are $27.12 \mathrm{MHz}$ $(11.05 \mathrm{~m}), 915 \mathrm{MHz}(37.24 \mathrm{~cm})$ and $2.45 \mathrm{GHz}(12.24 \mathrm{~cm})$ respectively. All domestic microwave ovens and dedicated microwave reactors for chemical synthesis use a frequency of $2.45 \mathrm{GHz}$ in order to avoid interference with telecommunications and radar frequencies.

It is known that Gamma Ray and X-Ray photons have sufficient energy to cause excitation of core electrons. Ultraviolet and visible irradiation are also used in photochemical reactions to excite valence electrons. However, by comparing the data in Table 1, it is clear that microwave irradiation cannot induce chemical reactions (Kappe et al., 2009).

The microwave photon (calculated by using Planck's law $E=h c / \lambda)$ at a frequency of $2.45 \mathrm{GHz}$ carries insufficient energy to cleave chemical bonds.

Microwave-related chemistry relies on the ability of materials to convert microwave irradiation into heat; the "heat generation" mechanism is related to the interaction of the molecules of a given material with microwaves (Mingos and Baghurst, 1991). Microwaves are electromagnetic waves which consist of an electric wave and a magnetic wave, with the magnetic wave oscillating at a $90^{\circ}$ angle to the electric wave. The electric wave has been shown to be the more important in these interactions (Gabriel et al., 1998; Mingos and Baghurst, 1997), although in some instances the magnetic field component has been shown to play a significant role (magnetic field interactions with transition metal oxides) (Timmel and Hore, 1996).

Table 1: Radiation photon energies compared to chemical bond energies (Nuchter et al., 2004)

\begin{tabular}{lllll}
\hline Radiation & Frequency $(\mathrm{MHz})$ & Quantum energy $(\mathrm{eV})$ & Bond type & Bond energy $(\mathrm{eV})$ \\
\hline Gamma rays & $3.0 \times 10^{14}$ & $1.24 \times 10^{6}$ & $\mathrm{C}-\mathrm{C}$ & 3.61 \\
X-Rays & $3.0 \times 10^{13}$ & $1.24 \times 10^{5}$ & $\mathrm{C}=\mathrm{C}$ & 6.35 \\
Ultraviolet & $1.0 \times 10^{9}$ & 4.1 & $\mathrm{C}-\mathrm{O}$ & 3.74 \\
Visible light & $6.0 \times 10^{8}$ & 2.5 & $\mathrm{C}=\mathrm{O}$ & 7.71 \\
Infrared light & $3.0 \times 10^{6}$ & 0.012 & $\mathrm{C}-\mathrm{H}$ & 4.28 \\
Microwaves & 2450 & 0.0016 & $\mathrm{O}-\mathrm{H}$ & 4.80 \\
Radiofrequencies & 1 & $4.0 \times 10^{-9}$ & Hydrogen bond $0.04-0.44$ & Brownian motion 0.0017 \\
\hline
\end{tabular}


The main effect derived from the interaction of the electric field component with material molecules is heating. Two main mechanisms (Kappe et al., 2009) are recognized today for this type of interaction: Dipolar polarization and ionic conduction.

The dipolar polarization mechanism (Mingos and Baghurst, 1991) applies only to polar materials and is based on the tendency of the dipoles to follow the inversion of the oscillating electric field (Fig. 4). Molecules, possessing dipole moment, align themselves in the applied electric field in a certain pattern and as the field oscillates the dipole matrix attempts to retain the induced pattern by realigning itself with the alternating electric field. This generates heat in the process through molecular friction and dielectric loss (Kappe et al., 2009). The amount of heat generated is proportional to the ability of the applied electric field to generate an optimal phase difference between the orientation of the electric field and that of the dipole matrix. If the phase difference is too large (the dipole matrix has no time to realign under high frequency irradiation) or too small (the dipole matrix re-aligns too quickly under low frequency irradiation), minimal heat is generated. The frequency of $2.45 \mathrm{GHz}$, used in dedicated microwave equipment, allows the dipole matrix to re-align without following the alternating field precisely. The phase difference thus generated causes thermal energy to be gained through molecular friction and collisions, in the form of dielectric heating.

The frequency of microwave irradiation is close to that of the rotational relaxation process, however, it is important to emphasize that the microwave-solvent interaction is not considered a quantum resonance phenomenon. There is no evidence to indicate the involvement of quantized rotational bands; microwaveinduced dielectric heating is a collective property involving aggregates of molecules (Kappe et al., 2009; Mingos and Baghurst, 1991; Mingos, 2005).

The ionic conduction mechanism (Mingos and Baghurst, 1991) applies to materials containing charged particles (such as ionic liquids etc). The dissolved charged particles, involved in an oscillatory motion under the influence of an alternating electric field, collide with adjacent molecules, generating heat in the process. The ionic conduction mechanism is considered to be just as efficient as the dipolar polarization mechanism in the heatgenerating process (Kappe et al., 2009).

\section{Microwave Heating or Conventional Heating?}

The traditional conductive heating of organic processes by external heat sources still plays a dominant role in organic chemistry. This process relies on the thermal conductivity of the reaction vessel materials, as well as convection currents within the vessel (Fig. 5a). The conductive heating is generally considered an inefficient method for transferring energy into the reaction; the temperature of the heat source and that of the vessel walls must necessarily be higher than the reaction medium, increasing the possibility of a temperature gradient being developed within the reaction medium from the vessel wall into the reaction bulk and this can lead to local overheating. In contrast, microwave heating is an irradiation process that raises the temperature of the vessel volume simultaneously, provided that the reaction vessels are not large (Fig. 5b). The reaction vessel itself is not affected thermally by microwave irradiation since it is made of microwave transparent materials, thus an inverted thermal gradient exists from the reaction bulk into the vessel wall, resulting in greatly reduced hot wall effects (Kappe et al., 2009).

Several other advantages displayed by microwave dielectric heating over conventional thermal heating are known:

The introduction of microwave energy into a reaction medium can lead to much higher heating rates than those achieved conventionally. Heating rates of $2-4^{\circ} \mathrm{Cs}^{-1}$ can be achieved readily for common organic solvents; such heating rates would require furnaces heated over $1000^{\circ} \mathrm{C}$ using conventional heating methods (Mingos, 2005; Stuerga and Lallemant, 1994).

The microwave-based technology allows for the remote introduction of microwave energy into the reactor; there is no direct contact between the energy source and the reaction vessel. Not only does it lead to faster heating rates, it also generates a significantly different temperature profile for the reaction (Fig. 6). At higher temperatures, the rate of chemical reactions using microwave irradiation is much higher and the reaction times shorter, so consequently the products also need remain a relatively shorter time in the process vessel. The "hot wall" effects are also eliminated as the temperature of the reactor walls is lower than that of the inner liquid volume. There are assumptions in the literature that temperature-sensitive reagents or catalysts may rapidly deteriorate at the hot vessel surface under conventional heating conditions. The elimination of such "hot wall" effects when heating using a microwave can increase the lifetime of catalysts and lead to better conversions. However, the lack of dedicated studies in this area to date makes it hard to quantify such effects (Kappe et al., 2009).

Microwave dielectric heating is a suitable method for accelerating chemical reactions under pressurized vessel conditions. It is possible to increase the temperature of a reaction in common organic solvents over $100^{\circ} \mathrm{C}$ above the conventional boiling point of the solvent using microwave irradiation (Mingos and Baghurst, 1997; Braunstein et al., 1987) Studies have shown that although the enthalpy of vaporization is the same under microwave and conventional heating conditions 
(Abtal et al., 1985), microwave-heated liquids boil at temperatures above their conventional boiling points at atmospheric pressure, mainly due to the remotely introduced mass-heating mechanism, that eliminates the role of nucleation points on reactor's surface (Kappe et al., 2009). For example, the microwave dielectric heating of ethanol $\left(\mathrm{bp}=79^{\circ} \mathrm{C}\right)$ in a closed vessel at $164^{\circ} \mathrm{C}$ lead to a pressure of $12 \mathrm{~atm}$. Heating at this temperature will lead to an enhancement of about 103 in the reaction rate, as calculated by the Arrenius kinetic equation below:

$$
K=A e^{(-E a / R T)}
$$

Where:

$K=$ The reaction rate constant

$R=$ The gas constant

$A=$ The Arrenius pre-exponential factor

$E a=$ The activation energy of the reaction)
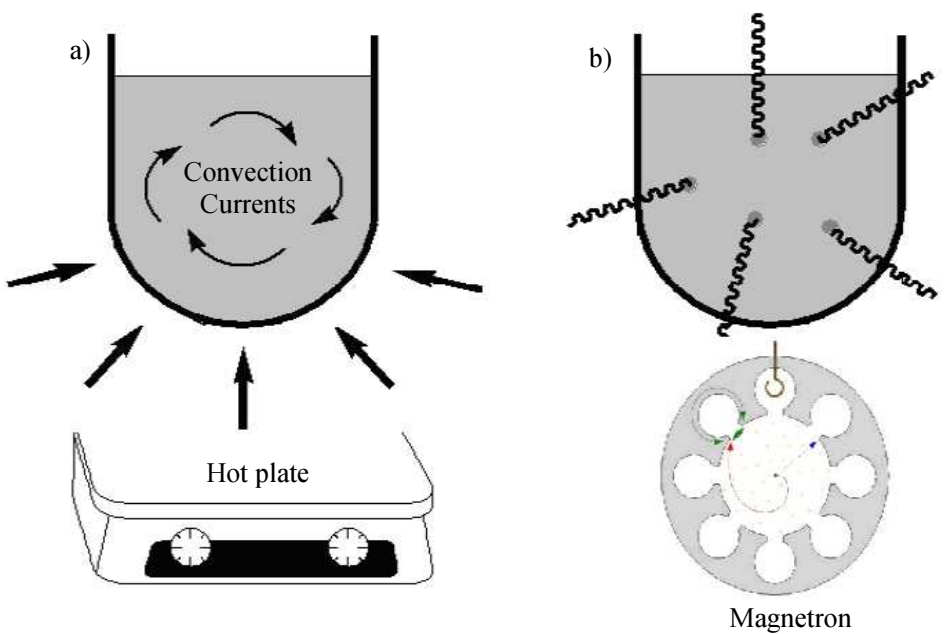

Fig. 5: Schematic comparison of conventional (a) and microwave heating (b) (Kappe et al., 2009)

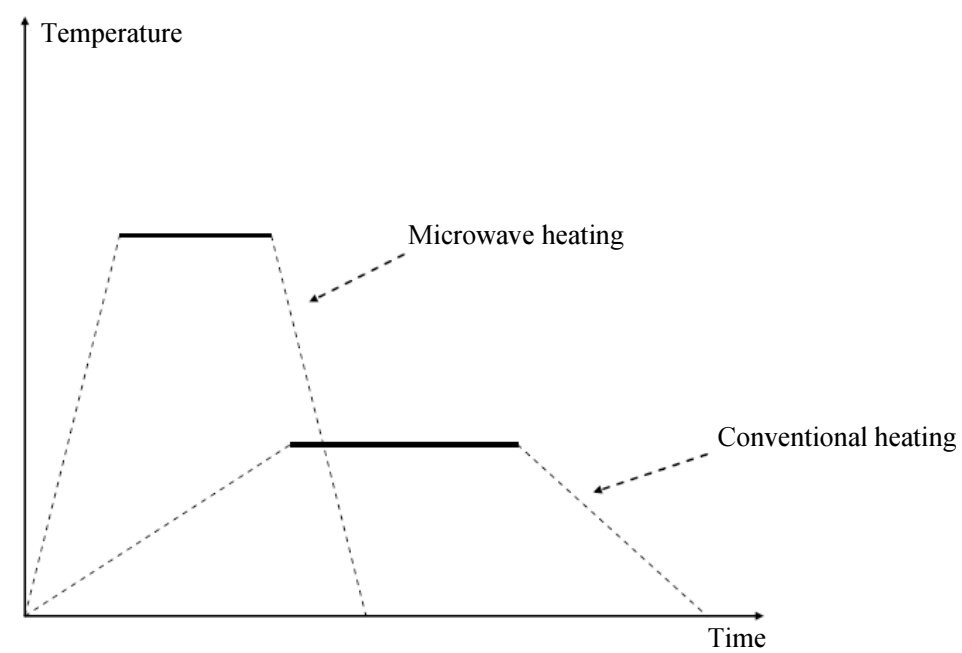

Fig. 6: The temperature-time profiles for conventional and microwave dielectric heating (using similar power setting) (Mingos, 2005) 


\section{Heterogeneous Reactions in Liquid Solvents}

Although precautions have to be taken in order to prevent electrical arcing, such as the use of lowmicrowave settings, high-boiling solvents and small well-dispersed metal particles (Mingos, 2005), the formation of "hot spots" due to the powerful coupling of microwave irradiation with metal nanoparticles or heterogeneous materials can accelerate greatly reaction rates (Zhang et al., 2003a). It is presumed that the temperature of the catalyst's surface is significantly higher than the bulk reaction medium (Kappe et al., 2009) and these localized "hot spots" can have an important impact on the outcome of the process. It has been shown that a very small number of superheated areas is sufficient to induce a substantial rate enhancement $(2 \%$ of hot spots can increase reaction yield by up to $60 \%$ ), even if their effects on the averaged process temperatures cannot be detected (Mingos, 2005; Stuerga et al., 1996). Several successful strategies have also been reported detailing synthetic protocols that involve reagents on solid supports such as silica and alumina (Gedye et al., 1986). As an example, the selective heating of $\mathrm{Pd} / \mathrm{C}$ catalyst was utilized in the hydrogenation of diphenylbutadiene 19 (Scheme 5). Microwave irradiation of this heterogeneous transformation gave complete conversion after $5 \mathrm{~min}$, whereas the same reaction performed under conventional heating proceeded with only $55 \%$ conversion. The use of a fiberoptic sensor ensured accurate temperature monitoring in both cases (Vanier, 2007).

\section{Homogeneous reactions Containing Polar Additives}

The scope of microwave dielectric heating can be extended to solvents, normally transparent to microwaves, that contain polar additives (Kappe, 2004; Kaiser et al., 2000). The energy of such polar molecules, known as "molecular radiators", is assumed to dissipate extremely fast into cooler surroundings (Mingos and Baghurst, 1991; Mingos, 2005) because it has been shown that is not possible to store the microwave energy in a specific part of the polar molecule by selectively activating the polar functional groups (Gabriel et al., 1998; Laurent et al., 1995). The inclusion of only $2 \%$ methanol in benzene (a microwave transparent solvent) ensures rapid heating of the solvent mixture under microwave irradiation, which couples effectively only with the methanol molecules. However, the rate of energy transfer through molecular collisions is so fast that the benzene molecules are also heated rapidly (Mingos, 2005).

\section{Microwave Effects}

It is now generally accepted that the major contribution of microwave irradiation technology to chemical synthesis is the generation of thermal effects, that are responsible for the dramatic rate enhancements (Kappe, 2004). Such rate enhancement can be rationalized by purely thermal/kinetic considerations (Mingos and Baghurst, 1991) on the basis of the Arrhenius kinetic law (Section 2.1). The pre-exponential factor $A$ and activation energy $E a$ remain unchanged for the purpose of the thermal effects (Kappe et al., 2009).

In addition, microwave effects that are caused by the uniqueness of the microwave dielectric heating mechanisms are also recognized. These effects, known as "specific microwave effects", are capable of accelerating the process kinetics in a manner that cannot be duplicated by conventional heating. However, these effects essentially remain thermal effects (Kappe, 2004).

\section{Non-Thermal Effects}

In addition to the thermal effects mentioned above, there are believed to be unique effects associated with microwave irradiation that cannot be explained by purely thermal considerations. These non-thermal, or athermal effects, result from the direct interaction of the electric field with specific molecules in the reaction medium. This affects the orientation of polar molecules, which affects either the pre-exponential factor $(A)$ or the activation energy $(E a)$ in the Arrhenius equation in the previous section.

It has been argued that the application of a microwave field to dielectric materials induces rapid rotation of molecular dipoles, which increases the probability of contact between molecules and then collision efficiency. The pre-exponential factor $A$, which represents the probability of efficient molecular collisions, is descibed by the following expression:

$$
A=\gamma \lambda^{2} \Gamma
$$

Where:

$\gamma=$ A geometric factor which includes the number of nearest-neighbour jump sites

$\lambda=$ The distance between adjacent lattice planes - the jump distance

$\Gamma=$ The jump frequency, which is directly proportional to the vibration frequency of atoms at the reaction interface)

An increase in molecular mobility under microwave irradiation increases the pre-exponential factor $A$, therefore increasing the rate of reaction (Pereux and Loupy, 2001).

A typical example is provided in the microwave synthesis of titanium carbide (Binner et al., 1995) as shown in Scheme 6. 
The reaction rate using microwave irradiation was 3.4 times higher than the rate found with conventional heating, which could be explained by the pre-exponential factor being 3.4 times higher during microwave heating with no change in activation energy.

The decrease in the free activation energy $\Delta \mathbf{G}^{*}$ is considered another major non-thermal effect of microwave irradiation. Considering that $\Delta \mathbf{G}^{*}$ consists of an enthalpy and an entropy term $\left(\Delta \mathbf{G}^{*}=\Delta \mathbf{H}^{*}\right.$ $\left.\mathbf{T} \mathbf{\Delta} \mathbf{S}^{*}\right)$, it has been predicted that microwave irradiation generates a more "ordered" environment as a consequence of dipolar polarization; as a result, the entropy term $\mathbf{T} \mathbf{\Delta} \mathbf{S}^{*}$ would increase in a microwaveirradiated medium, in turn decreasing $\mathbf{\Delta} \mathbf{G}^{*}$ (Pereux and Loupy, 2001; Langa et al., 1997; Westaway and Gedye, 1995). Experimental evidence for this assumption has been provided in the microwaveassisted intramolecular imide formation of polyamic acid (Lewis et al., 1992) (Fig. 7). The $\mathbf{\Delta} \mathbf{G}^{*}$ factor is clearly reduced in the case of microwave heating and that has been attributed to a non-thermal microwave effect. It has been argued that when the polarity of reaction intermediates or transition state species is increased on going from starting materials to the transition state, the stabilization of the transition state species is more effective that of the starting materials, resulting in an enhancement of reactivity by a decrease in the activation energy (Kappe et al., 2009; Langa et al., 1997; Abramovich, 1991) (Fig. 8).

Similarly, it has been argued that a non-thermal microwave effect should be more pronounced for reactions that occur via a late transition state with an high activation energy. The transition state in this case is more prone to developing increased polarity, when compared to a reaction that occurs via an early transition state with only a small difference in polarity from the starting materials (Kappe et al., 2009; Pereux and Loupy, 2001; Langa et al., 1997; Abramovich, 1991).

A typical example to support this effect has been provided in the form of two irreversible Diels-Alder cycloadditions, performed over an extended time interval under both conventional heating and microwave irradiation conditions in order to balance any uneven thermal effects (Scheme 7) (Loupy et al., 2004).<smiles>Cc1ccc(C(=O)O)c(C(=O)Nc2cccc(N)c2)c1</smiles><smiles>Cc1cccc(N2C(=O)c3ccc(C)cc3C2=O)c1</smiles>

(a)

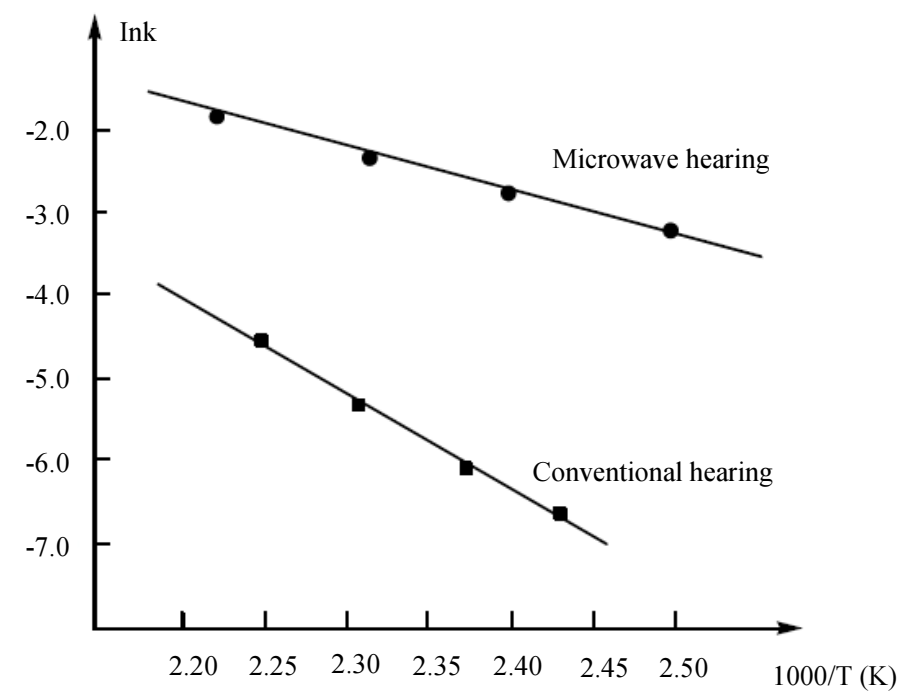

\begin{tabular}{lc}
\hline $\begin{array}{l}\text { Activation } \\
\text { mode }\end{array}$ & $\Delta \mathrm{G}^{*}(\mathrm{kj} / \mathrm{kmol})$ \\
\hline Microwave & $57 \pm 5$ \\
Conventional & $105 \pm 14$
\end{tabular}

(b)

Fig. 7: (a) Intramolecular imide formation of polyamic acid (Lewis et al., 1992); (b) Arrhenius plots for the imide formation via microwave irradiation and conventional heating 


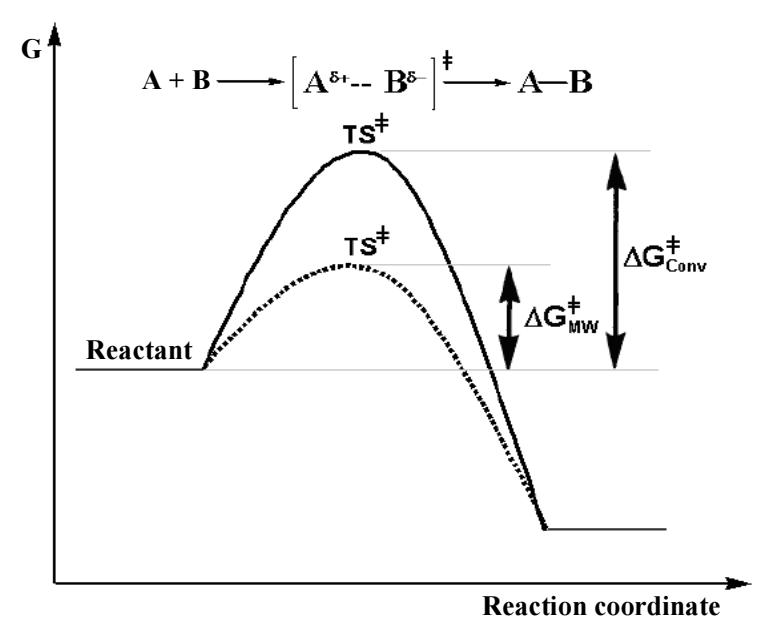

Fig. 8: Proposed stabilization of reaction intermediate species under microwave irradiation via lowering of transition state energy

Detailed $a b$ initio calculations of the two reactions revealed a concerted isopolar mechanism for the first reaction in Scheme 7a, with no charges and therefore no polarity developed in the transition state. Performed under microwave irradiation conditions, the yield of this reaction was the same when heated by microwave or conventional heating. On the contrary, the second reaction in Scheme $7 \mathrm{~b}$, for which the $a b$ initio calculations revealed a significant charge development in the transition state, performed significantly better under microwave irradiation conditions. According to the authors, the difference in the reaction yield for the second reaction is a clear indication of the existence of non-thermal effects that stabilize the polar transition state, thus lowering the activation energy of the microwave-assisted reaction pathway. This consequence does not exist in the first reaction due to the lack of electrostatic interactions of electric field with the transition state (Loupy et al., 2004). However, a re-investigation of the second Diels-Alder reaction in Scheme $7 \mathrm{~b}$, using a fiber-optic sensor technology in order to obtain accurate temperature readings, revealed no differences in yield between oil-bath and microwave irradiation conditions. This result was attributed to thermal effects playing the same role in both heating methods (conducted at an accurately-recorded temperature), rather than invoking a special non-thermal microwave effect (Herrero et al., 2008).

The above example, as well as other arguments that support the existence of non-thermal microwave effects are still the subject of considerable debate and controversy (Kuhnert, 2002). It is the opinion of some of the leading experts in this field that the concept of nonthermal microwave effects has to be critically reexamined and further evidence presented in order to reach a definite conclusion about the existence of such effects (Kappe, 2004).

\section{Microwave Technology}

The practice in the late 1980 s and early 1990s of conducting microwave-assisted synthesis in domestic microwave ovens has been abandoned today due to safety concerns (Kappe et al., 2009). Heating organic solvents in open vessels can lead to explosions induced by electric arcing and the lack of real-time pressure monitoring can lead to vessel rupture. Furthermore synthetic protocols often suffer from reproducibility problems due to the inhomogeneous nature of pulsed microwave irradiation.

Today, domestic microwave ovens have been replaced by dedicated microwave applicators in most research laboratories, which feature built-in temperature and pressure sensors and software that enables on-line temperature or pressure control. The main components of a dedicated microwave reactor are the magnetron (microwave generator), the waveguide (a transmission line that guides the microwave irradiation into the microwave cavity) and the cavity itself, which accommodates the reaction vessel. The magnetron (Fig. 9a), consists of a cylindrical cathode in the centre of a circular chamber, surrounded by an anode block possessing small cavities and the system is operated under vacuum. The electrons emitted from the cathode due to a high-voltage electric field are deflected by a magnetic field applied parallel to the cathode axis which causes electrons to spiral outwardly instead of gravitating straight into the anode. Sweeping inside the cavity, these electrons induce a high-frequency electromagnetic field, a portion of which is extracted by a short antenna connected to the waveguide. This in turn directs the induced microwave field into the instrument cavity and the microwave-generating efficiency of these devices is in the $65-70 \%$ range (Fig. $9 \mathrm{~b}$ ).

Early microwave applicators were multi-mode instruments, where the microwaves were reflected by the walls over a large cavity (similar to a domestic microwave oven) and interacted with the sample in a random manner. Although the samples were rotated inside the cavity, the density of the field around individual samples was low, despite the high microwave power being used (1000-1600 W) resulting in poor performance for small-scale reactions. This was addressed to a large extent in modern multi-mode instruments that can accommodate multiple reaction vessels in the presence of a homogeneous field.

The more recent single-mode microwave applicators also generate a homogeneous energy field of high density around the smaller cavity (Fig. 9b) despite relatively low power levels (typically 300-400 W). The homogeneity of the microwave field ensures sustained equipment performance and process reproducibility. The temperature on the surface of reaction vessels can be measured by a remote, built-in IR sensor, that does not always represent the actual temperature of the reaction bulk. The more expensive fiber-optic temperature probes, that can be immersed directly into the reaction vessel, are mainly available in larger, multi-mode microwave instruments. 


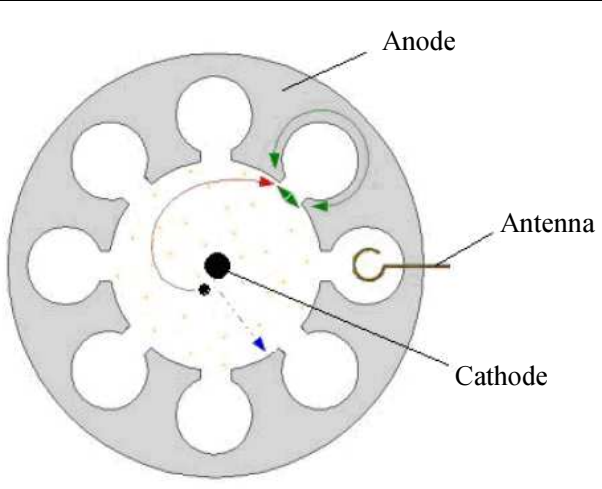

(a)

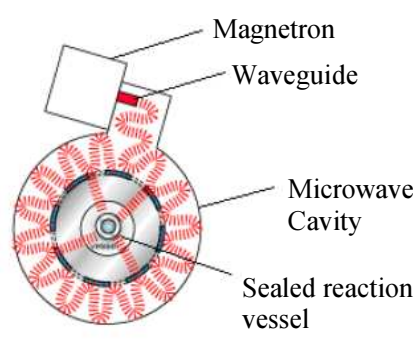

(b)

Fig. 9: (a) Cross-sectional view of a magnetron depicting the pathway of electrons under the applied magnetic field; (b) crosssectional view of a single-mode microwave cavity (Kappe et al., 2009)

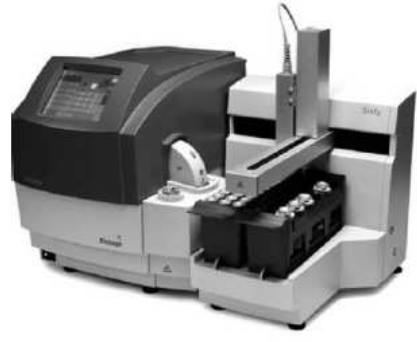

(a)

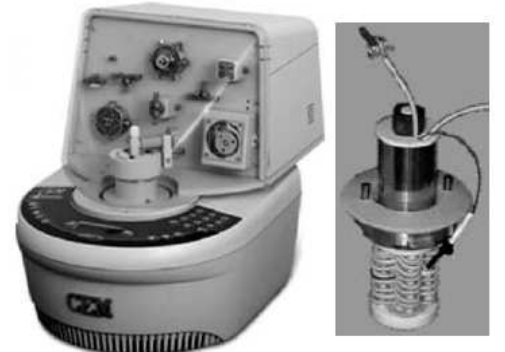

(b)

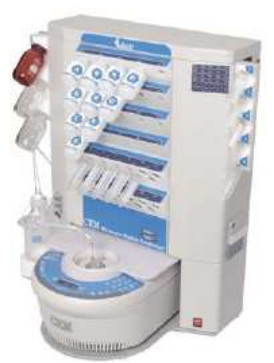

(c)

Fig. 10: Single-mode microwave instruments (a) Biotage Initiator 60, equipped with a rack and robotic arm; (b) CEM Voyager (flow instrument) and its flow cell; (c) CEM liberty peptide synthesizer

The steady performance of single-mode microwave instruments has been the driving force behind their design development. A number of instruments are now commercially available and in use in research laboratories, offering, among other features, flowthrough systems and solid phase peptide synthesis (Fig. 10) (Kappe et al., 2009).

\section{Microwave-Assisted Continuous Flow Technique as Technological Solution to Batch Microwave Scale- up Problems}

Reported initially in 1986 (Gedye et al., 1986) the advantages of Microwave-Assisted Organic Synthesis (MAOS) as an enabling technologyl has led to its use in a wide variety of applications (Kappe et al., 2009; Kappe, 2004; Larhed et al., 2002). The publication of more than 3500 manuscripts in this field (Glasnov and Kappe, 2007) is a strong indicator of the impact that this technique has had on synthetic organic methodology. MAOS protocols have been exploited successfully in drug discovery (Larhed and Hallberg, 2001), total synthesis (Baxendale et al., 2002), biochemical processes (Collins and Leadbeater, 2007), polymer synthesis (Bogdal et al., 2003c), nanotechnology (Tsuji et al., 2005) and materials science (Barlow and Marder, 2003).
The main technical limitation for single-mode microwave devices is the small cavity size, which generally allows the use of vessels no larger than 1-5.0 $\mathrm{mL}$; for that reason the majority of microwave-assisted reactions published to date have been conducted on a scale of less than $1.0 \mathrm{~g}$ (Kappe, 2004; Kremsner et al., 2006). However, in order to fulfill the demands of pharmaceutical and industrial applications, there is a need to develop larger-scale microwave-assisted protocols that can ultimately provide products on a multi-gram or even kilogram scale.

The limited penetration depth of microwave irradiation is perhaps the biggest challenge in scaling-up microwave-promoted protocols since it limits the size of the reaction vessel that can be used. Depending on the dielectric properties of particular solvents, the maximum penetration depth of $2.45 \mathrm{GHz}$ microwaves is on the order of few centimeters (Bogdal, 2005). Therefore microwave power density inside a large reaction volume may be negligible when compared to the surface density, thus invoking a convection heating mechanism (Fig. 5a) as opposed to microwave dielectric heating (Loupy, 2002). Consequently, as the size of the reaction vessel increases, it becomes more difficult to heat the larger reaction volume, requiring additional microwave power. However, as the capacity of the microwave reactor 
increases to $5000 \mathrm{~W}$ power levels, the standard aircooling in magnetrons is replaced by more sophisticated oil-based cooling, a factor that introduces more complexity and cost into the system (Kremsner et al., 2006; Loupy, 2002). This consideration, the low energy efficiency of converting electricity into microwave power $(65-70 \%)$ and safety concerns such as potential rupturing of large pressurized reactors, make the microwave approach less attractive for large-scale processing (Glasnov and Kappe, 2007; Kremsner et al., 2006). It is the opinion of several experts (Kirschning et al., 2006; Jas and Kirschning, 2003; Glasnov and Kappe, 2007; Kremsner et al., 2006; Loupy, 2002; Comer and Organ, 2005a) in this field that the solution to this problem is the combination of two "enabling" technologies: Microwave heating and flow processing, in the form of microwave-assisted continuous flow technology.

In addition to advantages associated with continuous flow methodology, the microwave-assisted, continuous flow approach is an appealing alternative to scaling-up MAOS protocols for several reasons:

It solves the scalability issues without the need for further optimization, by using the scale-out and/or numbering-up approach. Once the reaction conditions are optimized for the continuous flow protocol, substantial amounts of product can be obtained by operating the system for a long time interval or running several reactors in parallel under identical conditions (Comer and Organ, 2005b).

It eliminates the safety concerns associated with powerful microwave heating of large pressurized reactors. These concerns are negligible due to lower reaction volumes, smaller instrument cavities and small scale reactors.

It bypasses the physical limitations of batch MW instruments such as penetration depth and power constraints. Moreover, energy transmission is higher in smaller cavities; low power magnetrons are suitable and therefore the process is more economical.

It offers the possibility of full system automation, resulting in a considerable reduction of processing time and labour (Kremsner et al., 2007).

One problem associated with the continuous flow approach is the limited "residence time" that any one plug of a reaction mixture experiences under microwave irradiation. Further, processing heterogeneous mixtures in flow poses its own hurdles. The former problem can be dealt with to a great extent by using coil-based designs for flow reactors that can increase the residence time. As for handling slurries and solid reagents, peristaltic pumps have been demonstrated to be effective in this regard (Kappe et al., 2009; Kremsner et al., 2007).

\section{Microwave-Assisted Fluidic Systems and their Applications}

\section{Microscale Fluidic Systems}

The numerous microwave-assisted, continuous flow systems in operation today exemplify the successful application of the two "enabling" technologies in conjunction, microwave heating and flow processing.

Cablewski et al. (1994) were the first to develop and utilize a microwave-assisted continuous flow quartz reactor (Fig. 11) that provided accurate pressure and temperature control. The reactor was operational at $200^{\circ} \mathrm{C}$, incorporating a back-pressure of 14 bar. In order to prove the reliability of the microwave-assisted continuous flow concept, over 20 reactions, including nucleophilic substitutions, Diels-Alder cycloadditions, esterifications, base- and acid-catalyzed hydrolyses, isomerizations, decarboxylations, eliminations etc., were performed at temperatures up to $100^{\circ} \mathrm{C}$ higher than the boiling point of the solvents at standard conditions, which accelerated the reactions by as much as three orders of magnitude.

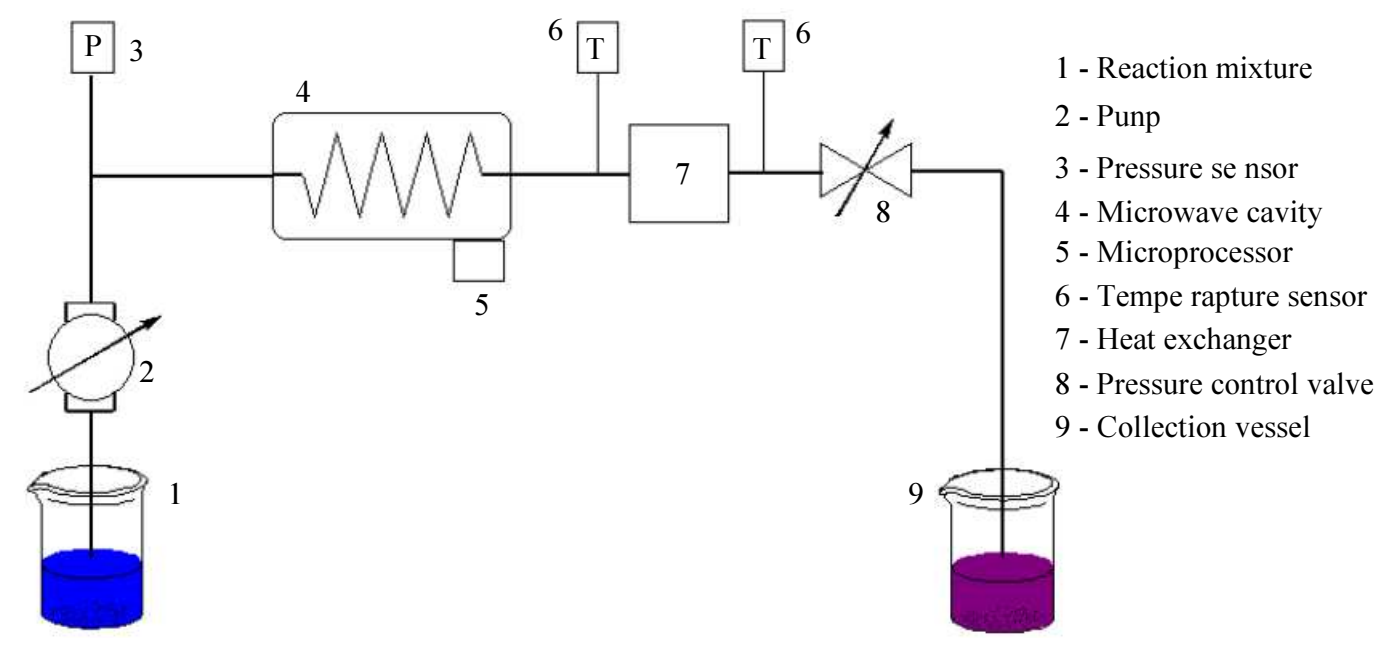

Fig. 11: Schematic design of the continuous flow system developed by Strauss (Bremner and Organ, 2007) 


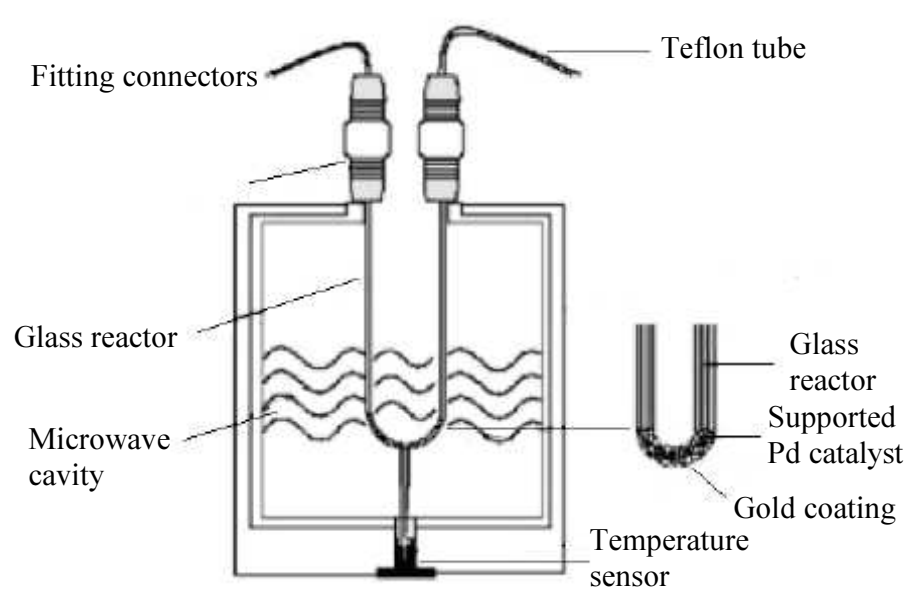

(a)

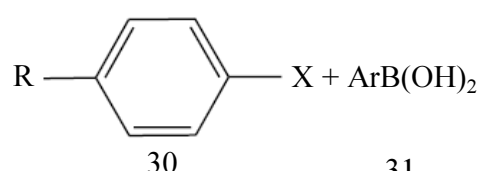

30
31

$\mathrm{X}=\mathrm{Br}, 1$

$\mathrm{R}=\mathrm{CN}_{2}, \mathrm{CHO}, \mathrm{OCH}_{3}, \mathrm{CH}_{3}$

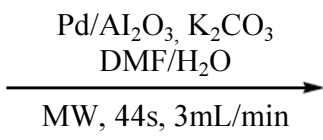

(b)

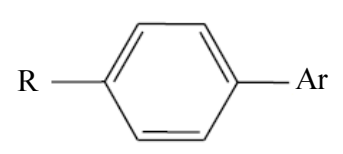

32

5 reactions $58-99 \%$ conversion

Fig. 12: (a) Continuous flow reactor built by Haswell; (b) Suzuki-Miyaura cross-coupling reactions conducted in flow using the above reactor (Jachuck et al., 2006)

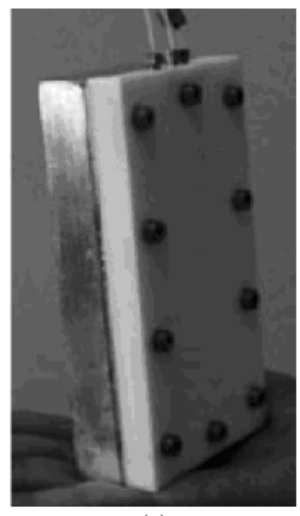

(a)<smiles>O=Cc1cccc(OC(=O)O[Na])c1</smiles>

34

$75 \%$ conversion

Fig. 13: (a) Isothermal continuous flow reactor built by Jachuck; (b) oxidation of benzyl alcohol conducted in flow using the above reactor (Jachuck et al., 2006)

A custom-built glass-chip reactor was designed by Haswell et al. (Fig. 12a) that incorporated an immobilized $\mathrm{Pd}$ catalyst $\left(\mathrm{Pd} / \mathrm{Al}_{2} \mathrm{O}_{3}\right)$, which was re-used several times in a heterogeneous Suzuki-Miyaura crosscoupling protocol (Fig. 12b) (He et al., 2004). Coating the outside of the catalyst channel with a strongly microwave-absorbent gold layer proved to be effective in generating the necessary heat for the reaction.

Jachuck et al. (2006) have reported the use of an isothermal continuous flow microreactor (Fig. 13a) in the oxidation reaction of benzyl alcohol by $\mathrm{Fe}\left(\mathrm{NO}_{3}\right)_{3} \cdot 9 \mathrm{H}_{2} \mathrm{O}$ (Fig. 13b). The sealed Polytetrafluoroethylene (PTFE) microreactor consists of reaction zone microchannels (270 $\mu \mathrm{L})$ that interface with heat exchange microchannels (600 $\mu \mathrm{L}$ ). The reactor is placed in a microwave cavity and the heat generated in the reaction zone is absorbed by water flowing inside the heat exchanger. This approach allowed the system to operate under isothermal conditions where the reaction temperature fluctuated by less than $0.3^{\circ} \mathrm{C}$ during the process. 


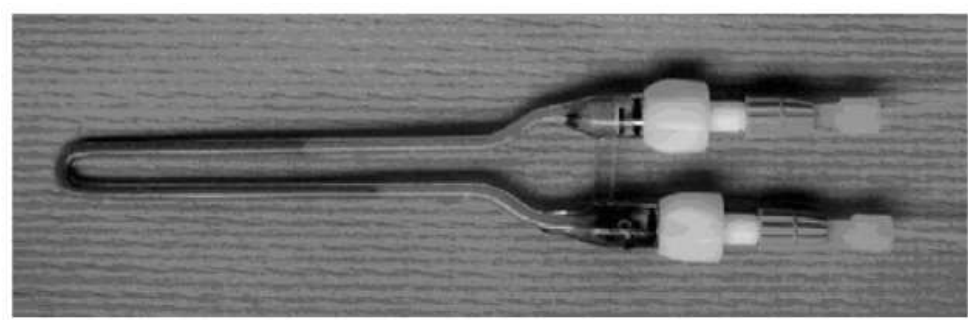

(a)

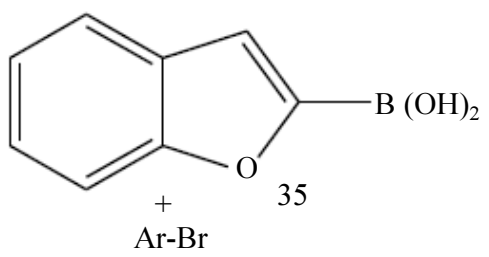

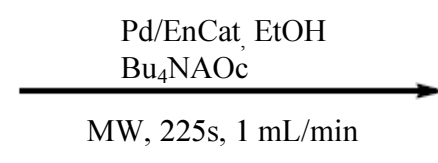

(b)

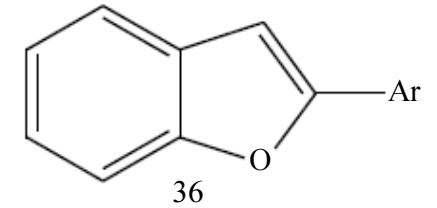

5 reactions $81 \%$ conversion

Fig. 14: (a) U-shaped tubular microreactor built by Ley filled with Pd EnCat catalyst; (b) Suzuki-Miyaura cross-coupling protocol conducted in flow using the above reactor (Baxendale et al., 2006c)

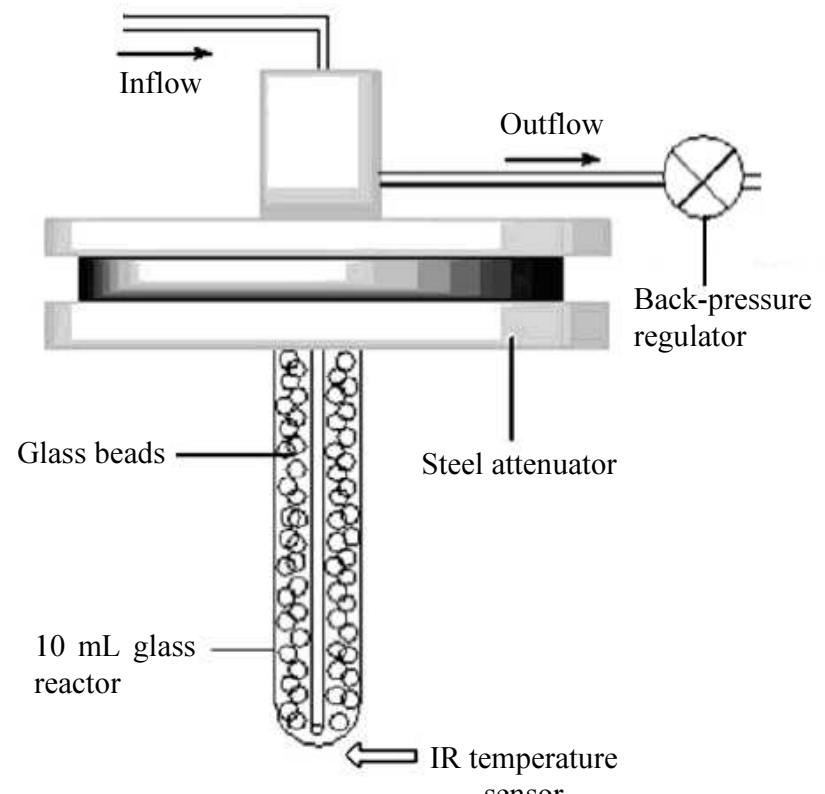

(a) sensor<smiles>CCOC(=O)C1=C(C)N=C(NC)SC1c1ccccc1</smiles>

37

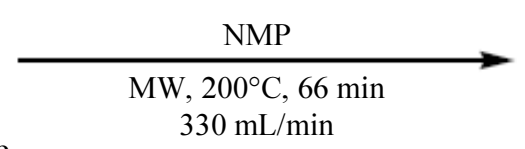

(b)<smiles>CCOC(=O)C1=C(C)NC(=S)N(C)C1c1ccccc1</smiles>

$88 \%$ conversion

Fig. 15: (a) Continuous flow reactor designed by Kappe (b) Dimroth rearrangement conducted in flow using the above reactor (Glasnov et al., 2006) 
Baxendale et al. (2006c) employed successfully a U-shaped continuous flow reactor (Fig. 14a) in Suzuki- Miyaura cross-couplings (Fig. 14b), using a polyurea microencapsulated Pd catalyst (Pd EnCat). Applying pulsed microwave irradiation followed by short gas-jet cooling extended the life of the catalyst to the point that cross-coupling products were synthesized without the need for catalyst regeneration.

Glasnov et al. (2006) used a rather unique reactor design (Fig. 15a) to conduct a Dimroth rearrangement of 1,3thiazines into substituted dihydropyrimidines (Fig. 15b). The reactor was designed by fitting a standard $10 \mathrm{~mL}$ Pyrex tube with a custom-built steel head. The inner space of the reactor was filled with $2 \mathrm{~mm}$-sized glass beads in order to create microchannels that would increase the residence time of the reaction mixture in the microwave heating zone. The system was placed in the cavity of a CEM Voyager (Fig. 10b) and the reaction mixture was pumped from the bottom of the reaction vessel and forced to move upwards through the glass beads.

Using a similar reactor design to the one shown in Fig. $15 \mathrm{a}$, although their reactor was filled with sand instead of glass beads, Bagley et al. (2005) successfully conducted the Bohlmann-Rahtz synthesis of pyridines by cyclodehydration of the corresponding aminodienones.

Kunz et al. (2005) also developed a unique continuous flow reactor composed of composite polymer materials in the form of rings, supported by a steel frame (Fig. 16a). Immobilization of the $\mathrm{Pd} 0$ catalyst on the inner reactor surface was carried out by pumping a Pd solution through the ring wall then reducing $\mathrm{Pd}$ with a sodium borohydride solution, that led to the formation of Pd nanoclusters on the reactor surface (Fig. 16b). The palladated reactor was placed in the cavity of a CEM Voyager (Fig. 10b) and was utilized in several synthetic applications, including a Heck cross-coupling reaction (Fig. 16c).

Another custom-made flow reactor was reported by Wilson et al.81 The flow cell, consisting of a glass coil encased in a protective glass sheath (Fig. 17a), was designed to process reaction mixtures on a multi-gram scale ( $4.0 \mathrm{~mL}$ total flow cell volume). Inserted into the cavity of a single-mode microwave reactor (Emrys Synthesizer, similar to the one shown in Fig. 10a), the system was operated either in open- or closed-loop mode. Temperature measurements were performed by the internal IR sensor of the instrument and pressure fluctuations were prevented by the use of a back-pressure regulator mounted at the outlet tubing. A variety of Suzuki- Miyaura cross-coupling reactions, esterifications and nucleophilic aromatic substitution (Fig. 17b) were efficiently performed under microwave irradiation conditions.

\section{The Stop-Flow Protocol}

The Stop-Flow protocol is a microwave-assisted technique developed recently $54 \mathrm{~b}$ in order to facilitate microwave processing on a gram scale; the technique is mainly suited to process heterogeneous mixtures that can be incompatible with other fluidic systems. The standard equipment for this technique is the CEM Voyager used in conjunction with the flow cell, as shown in Figure 10b. The reagent mixtures are pumped into the vessel using peristaltic pumps capable of processing slurries of reagents. The system is sealed and all processing occurs under pressurized conditions; afterwards the processed mixture is discharged from the vessel automatically and the system is ready to receive the next batch.

(a)
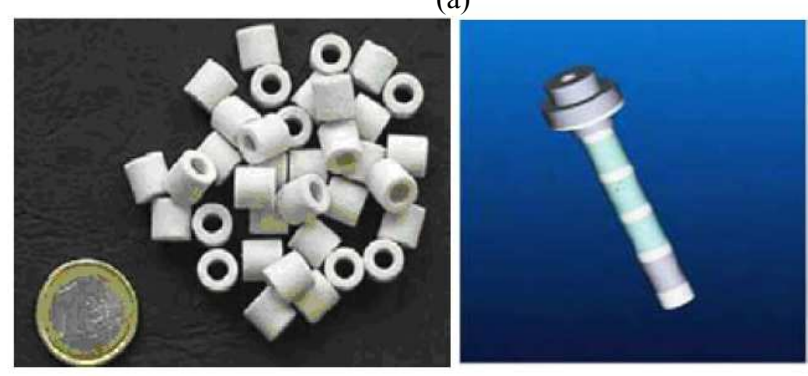

(b)

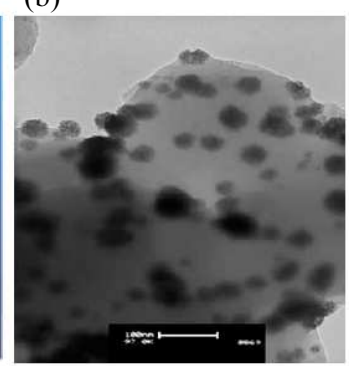

(c)

39<smiles>C=CC(=O)OC(C)(C)C</smiles>

40

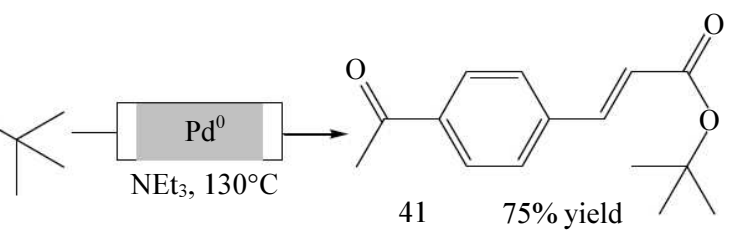

Fig. 16: (a) The composite ring reactor designed by Kirschning; (b) SEM image of Pd nanoclusters on the reactor surface (scale shown is $100 \mathrm{~nm}$ ); (c) Heck cross-coupling conducted in flow using the above reactor (Glasnov and Kappe, 2007; Kunz et al., 2005) 


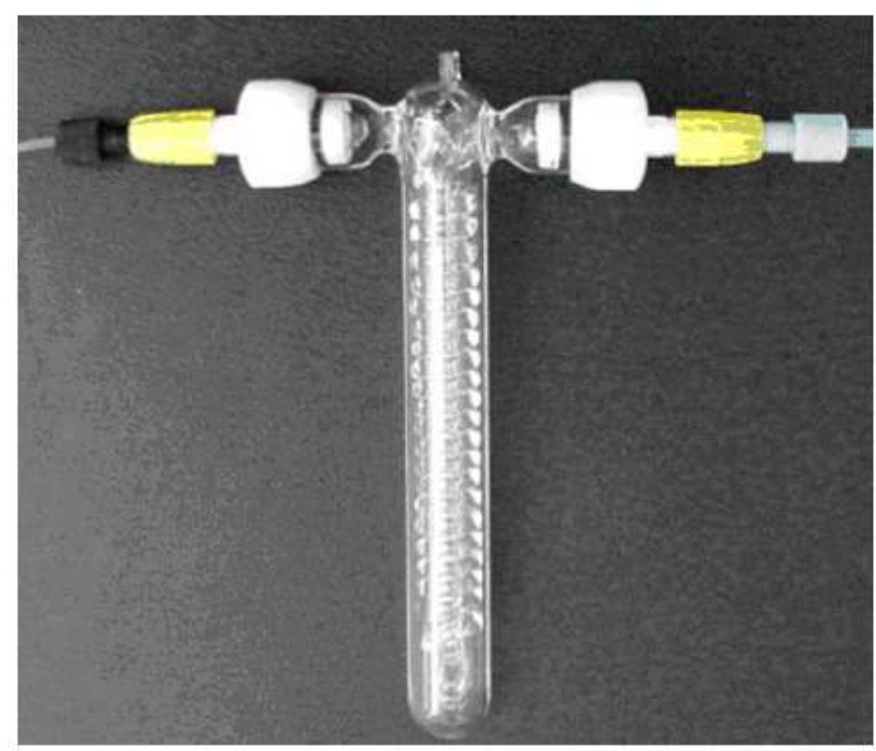

(a)<smiles>O=[N+]([O-])c1ccccc1F</smiles>

42<smiles>NCCc1ccccc1</smiles>

43

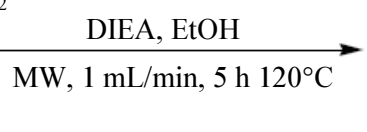

(b)<smiles>O=[N+]([O-])c1ccccc1NCCc1ccccc1</smiles>

$81 \%$ conversion

Fig. 17: (a) The coiled glass reactor designed by Wilson (b) microwave-assisted nucleophilic aromatic substitution conducted in flow using the above reactor (Wilson et al., 2004)

Using the stop-flow approach, Arvela et al. (2005) successfully scaled-up the Suzuki-Miyaura coupling of phenyl boronic acid and 4-bromoacetophenone as well as the Heck cross-coupling of styrene with 4-bromoanisole. The optimized reaction conditions on a $1.0 \mathrm{mmol}$ scale for both protocols were introduced readily to a stop-flow strategy on a $10 \mathrm{mmol}$ scale using the CEM Voyager instrument. A process cycle of 10 consecutive runs provided, respectively, $18.5 \mathrm{~g}$ the Suzuki-Miyaura product (95\% yield, $50 \mathrm{~min}$ total time) and $14.9 \mathrm{~g}$ of the Heck product (71\% yield, 200 min total time).

In a similar manner, Loones et al. (2005) performed several Pd-catalyzed amination reactions of 4chloroanisole with morpholine using the CEM Voyager reactor. The stop-flow approach allowed for the smooth transition of optimized reaction conditions, from a 1.0 mmol to a $20 \mathrm{mmol}$ scale. A process cycle of 12 consecutive runs provided an overall yield of $76 \%$ for the amination product (190 $\mathrm{min}$ ).

These examples, as well as several others (Mingos and Baghurst, 1991; Glasnov and Kappe, 2007) detailing the utility of microwave assisted continuous flow technology for larger scale processes in semi-pilot and pilot plant industrial applications, indicate the great potential of the microwave-assisted continuous flow approach in combinatorial chemistry and other synthetic applications.

\section{Using Metals-in-Microwave Approach: Extremely Fast Synthesis in Flow}

Developed after 2005 by Shore et al. (2010; Comer and Organ, 2005a; Bremner and Organ, 2007) this approach dealt successfully with a sharp problem arising from irradiating reactions in flow format: Typically small fractions of microwave power are converted into heat during the irradiation process resulting in low efficiency of microwave energy transfer to the reaction medium. When considering the usually brief "residence time" (the time that a reaction plug spends inside the flow reactor, ranging from several seconds to several minutes) and the limited number of microwave-absorbing organic solvents, the temperatures achieved inside the flow reactor are often low and the heat thus generated is insufficient to drive reactions to completion. Attempts to use powerful microwave instruments do not truly address this problem because such undertaking does not improve the efficiency of microwave-solvent interactions. 
Metals-in-Microwave as a state-of-the-art solution to this problem, focused on changing the conceptual basis on which the previous microwave-assisted, continuous flow technology was founded. Instead of focusing on microwave-reaction medium interactions, this new approach focused on the microwave-reaction vessel interactions in order to instantaneously generate and maintain sufficient process temperatures during the brief residence time.

Based on carefully designed protocols, metal-coated microreactors were prepared (Fig 18a) in order to serve as reaction vessels under microwave irradiation; the thickness of metal films, as an integral part of these microreactors was maintained between 2-3 $\mu \mathrm{m}$. There were two advantages that this technological approach brought compared to other microwave-assisted, flow systems in use today:

1. Due to an enormous amount of heat generated on the metal film (Fig 18b) using a minimal power setting of 25-35 W the reaction kinetics were tremendously accelerated

2. The thin metal films, besides serving as heating elements, were also catalytically active under microwave irradiation, due to their very porous morphology containing metal nanoclusters which extended into the reaction medium (Fig 18c)

This approach was used in a number of diverse synthesis in flow, in which the reaction time was significantly shortened to 2-4 min, down from 48-72 hours typically needed for conventional synthesis.

Pd-coated microreactors were used initially to conduct extremely fast Suzuki-Miyaura and Heck crosscoupling reactions (Shore et al., 2006). Both reactions were complete within a 2 min interval, being conducted in the absence of an external Pd catalyst as $\mathrm{Pd} 0$ nanoclusters (of thin Pd film lining the inside of flow microreactors) provided the catalysis for both processes.

Other applications of Pd-coated microreactors include fast synthesis of Diels-Alder cycloadducts (Shore and Organ, 2008b) in one of first ever examples of this methodology being conducted in flow and flow synthesis of substituted indoles, using an elegant 2-step (amination/Heck) cascade protocol (Scheme 8).

Inclusion of an external catalyst (Pd-PEPSSI IPr) in this case presents a very interesting example of a homogeneous Pd catalyst working in tandem with heterogeneous $\mathrm{Pd}$ nanoclusters to catalyze this complex methodology.

Gold-coated microreactors were also used in a number of mechanistically-diverse gold-catalysed organic transformations such as alkyne hydrosilylations and benzannulation reactions.

Firstly, the hydrosilylation of terminal alkynes was conducted in flow utilizing catalysis by thin Au films that proved to be very efficient85c in one of the first ever protocols to replace catalysis by benchmark catalysts such as Karsted's catalyst and Speier's catalyst with that of $\mathrm{Au}^{0}$ thin films. This protocol not only tolerated a wide moiety of substrates, the $E$ selectivity for the terminal silane product was always greater than $90 \%$.

In mechanistically complex benzannulation reactions, alkynes were flowed together with alkynyl-substituted benzaldehyde derivatives in gold-coated microreactors in order to generate substituted naphthyl ketones (Shore et al., 2009; Shore and Organ, 2010). Again, very good yields were obtained for a wide variety of products (Scheme 9).

In another original application, $\mathrm{Cu}$-coated microreactors were used in the complex synthesis of propargyl amines via a three-component reaction protocol (Shore et al., 2010; Shore and Organ, 2010). The thin $\mathrm{Cu}$ films provided the catalysis for the condensation process involving an amine, alkyne and aldehyde, while the microwave irradiation of $\mathrm{Cu}$ films generated the necessary temperature for the process (Scheme 10).

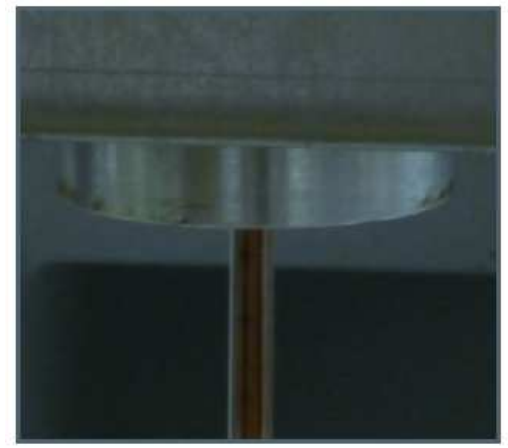

(a)

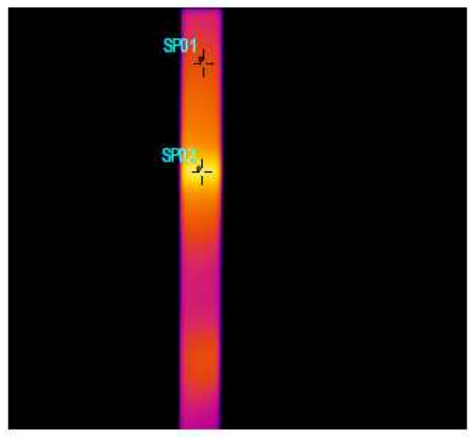

(b)

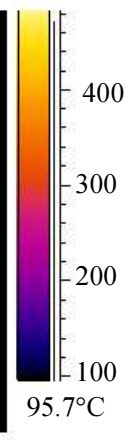

100

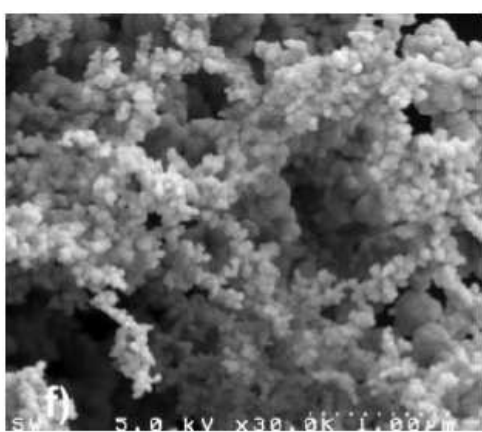

(c)

Fig. 18: (a) Metal-coated microreactor (ID $=1700 \mu \mathrm{m}$ ) residing inside the irradiation chamber of a dedicated microwave instrument; b) thermal image of a metal-coated microreactor under microwave irradiation conditions. The image represents a partial reactor length of $3 \mathrm{~cm}$ (total length is $12 \mathrm{~cm})$ inside the microwave chamber. Spol $\left(352^{\circ} \mathrm{C}\right)$ and $\mathrm{Spo} 2\left(474^{\circ} \mathrm{C}\right)$ are the temperature readings at different points on the surface of the microreactor; c) Scanning Electron Microscopy (SEM) image of developed Pd nanoclusters, obtained at $\times 30,000$ magnification (Shore, 2011) 


\section{Applications of Microwave Sensitive Reactors to Water Distillation Systems}

This application bears evidence to the fact that microwave-active reactors have an ever expanding reach not only in chemistry areas but environment as well. One of the most sensitive areas in this respect is the global water sanitizing situation. Unprecedented global population growth over the past decades have put a tremendous strain on the capabilities of current water sanitization technologies to provide the necessary potable water for the ever growing global population.

Today it is estimated that over $35 \%$ of the world population is suffering to some extent from lack of drinking water; that percentage will increase respectively to $40 \%$ by year 2025 and $50 \%$ by year 2045 .

The new microwave assisted water distillation device prototype, a product of one year cooperation between the
Humber School of Applied Technology and Mikroen Solutions Inc., is shown in Fig. 19. The device consists of three modules.

Once the brackish/saline water is loaded in the microwave sensitive distillation reactor, which is housed in the chamber 2 , the microwave generator 1 is switched on. The distillation process starts several minutes after the start of microwave irradiation as the temperature of the reactor is gradually increased to well over $100^{\circ} \mathrm{C}$. At this time the condensation unit 3 is switched on. The condensation unit consists of two aluminum blocks welded together; these blocks contain a spiral cavity on the inside for the distilled water flow. The cooling effect is achieved due to several self-cooling ceramic units lodged into specially prepared rectangular chambers on the outside of the blocks. Two fans are in direct contact with the hot face of the ceramic units for the purpose of dissipating accumulated heat.

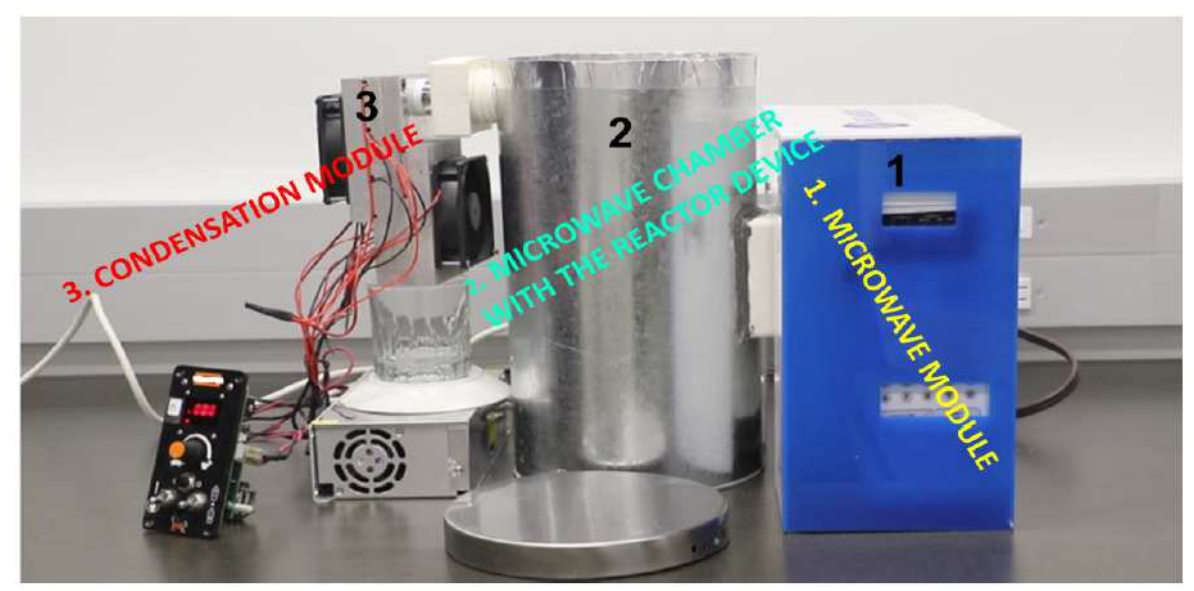

Fig. 19: Frontal view of the water distillation device prototype. (1) microwave generator module; (2) distillation reactor chamber; (3) water vapour condensation module

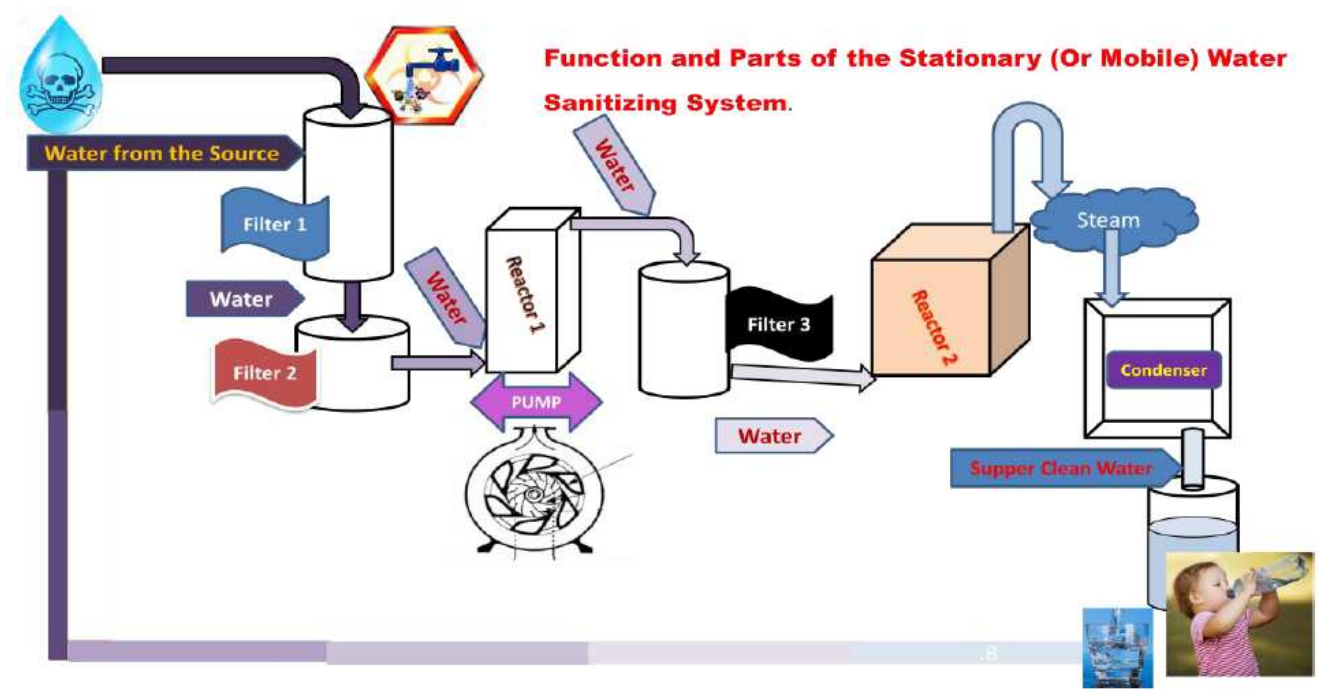

Fig. 20: General schematic of high throughput water sanitizing systems using microwave sensitive reactor technology 
The distilled water is collected in to the glass placed below the condensation unit; the measured distillation rate is approximately $100-110 \mathrm{~mL} / 6 \mathrm{~min}$ (approximately one liter of distilled water per hour). The applied microwave power is approximately 250 watts/hour, a feature that makes it possible for operation of the distillation unit to be supported by solar batteries alone, thus achieving independence from the power grid.

Similar technological applications will be built for high throughput water sanitizing systems, shown schematically in Fig. 20.

\section{Perspective}

The examples given in this review show that the departure from classical research platforms is necessary for rapid, continuous production of chemicals with minimum purification. As technological issues become an increasing part of daily chemical research, process and medicinal chemists alike are combining new methodologies and enabling technologies to create new synthetic platforms for conducting synthesis, including single as well as multistep catalytic transformations. Whatever chemists require, synthesis of few milligrams of a compound in drug discovery, or the preparation of kilogram quantities for clinical research, microwaveassisted continuous flow processes can deliver for them.

Furthermore continuous flow processes are considered a universal tool to allow the quick transition from laboratory research platforms to industrial research development, thus eliminating the time and materialconsuming optimization from small-scale reactions to a full production scale. While merits of flow synthesis such as the ability to monitor reaction in real time and make instantaneous changes to reaction conditions, have long been recognized the impact of this technology in the chemical sector is still small, primarily because of poor reaction kinetics during the brief time that reagents are flowed together in a flow reactor.

As time progresses, applications of microwaveassisted continuous flow or batch devices are not limited to chemical fields anymore. In the forthcoming years we are bound to see more and more environmental applications. The water decontamination by microwave irradiation for the purpose of generating potable water offers extremely wide opportunities to this technology, in a field where there is an immense vacuum for new water sanitizing technologies. The continuous flow distillation by microwaves addresses the scale up questions, without compromising the user safety. However the scope of applications for microwaveassisted devices is not limited to that. Biofuel generation via pyrolysis of waste, Pasteurization and Ultra High
Temperature processing of food derivatives and other similar applications are just a glimpse into the wide array of applications where the microwave active reactors can offer faster, ecologically friendly and non-energy intensive ways of achieving results.

\section{Acknowledgment}

We acknowledge the Humber School of Applied Technology and Humber Research for their unwavering support in completing the microwave-assisted decontamination device shown in this article.

\section{Author's Contributions}

All authors equally contributed in this work.

\section{Ethics}

This article is original and contains unpublished material. The corresponding author confirms that all of the other authors have read and approved the manuscript and there are no ethical issues involved.

\section{References}

Abtal, E., M. Lallemant, G. Bertrand and G. Watelle, 1985. Activation des liquides polaires sous champ microonde. J. Chem. Phys., 82: 381-389.

DOI: $10.1051 /$ jcp/1985820381

Acke, D.R.J., R.V.A. Orru and C.V. Stevens, 2006. Continuous synthesis of tri- and tetrasubstituted imidazoles via a multicomponent reaction under microreactor conditions. QSAR Comb. Sci., 25: 474-483. DOI: 10.1002/qsar.200540194

Arvela, R.K., N.E. Leadbeater and M.J. Collins, 2005. Automated batch scale-up of microwavepromoted Suzuki and Heck coupling reactions in water using ultra-low metal catalyst concentrations. Tetrahedron, 61: 9349-9355. DOI: $10.1016 / j$.tet.2005.07.063

Bagley, M.C., R.L. Lenkins, M.C. Lubinu, C. Mason and R. Wood, 2005. A Simple Continuous Flow Microwave Reactor. J. Org. Chem., 70: 7003-7006. DOI: $10.1021 /$ jo0510235

Barlow, S. and S.R. Marder, 2003. Single-mode microwave synthesis in organic materials chemistry. Adv. Funct. Mater., 13: 517-518. DOI: $10.1002 / \mathrm{adfm} .200301006$

Baxendale, I.R., C.M. Griffiths-Jones, S.K. Ley and G.K. Tranmer, 2006a. Preparation of the neolignan natural product grossamide by a continuous-flow process. SYNLETT, 3: 427-430.

DOI: $10.1055 / \mathrm{s}-2006-926244$ 
Baxendale, I.R., J. Deeley, C.M. Griffiths-Jones, S.K. Ley and S. Saaby et al., 2006b. A flow process for the multi-step synthesis of the alkaloid natural product oxomaritidine: A new paradigm for molecular assembly. Chem. Commun. DOI: 10.1039/B600382F

Baxendale, I.R., C.M. Griffiths-Jones, G.K. Tranmer and S.V. Ley, 2006c. Microwave-assisted suzuki coupling reactions with an encapsulated palladium catalyst for batch and continuous-flow transformations. Chem. Eur. J., 12: 4407-4416.

DOI: $10.1002 /$ chem.200501400

Baxendale, I.R., S.V. Ley, M. Nessi and C. Piutti, 2002. Total synthesis of the amaryllidaceae alkaloid (+)plicamine using solid-supported reagents. Tetrahedron, 58: 6285-6304. DOI: 10.1016/S0040-4020(02)00628-2

Binner, J.G.P., N.A. Hassine and T.E. Cross, 1995. The possible role of the pre-exponential factor in explaining the increased reaction rates observed during the microwave synthesis of titanium carbide. J. Mater. Sci., 30: 5389-5393.

DOI: $10.1007 / \mathrm{BF} 00351548$

Bogdal, D., 2005. Microwave-Assisted Organic Synthesis: One Hundred Reaction Procedures. 1st Edn., Elsevier, Oxford, ISBN-10: 0080446213, pp: 202.

Bogdal, D., P. Penczek, J. Pielichowski and A. Prociak, 2003c. Microwave assisted synthesis, crosslinking and processing of polymeric materials. Adv. Polym. Sci., 163: 194-263. DOI: 10.1007/b11051

Bouchard, L.S., S.R. Burt, M.S. Anwar, K.V. Kovtunov and I.V. Koptyug et al., 2008. NMR imaging of catalytic hydrogenation in microreactors with the use of para-hydrogen. Science, 319: 442-445.

DOI: $10.1126 /$ science. 1151787

Braunstein, P., M.A. Luke, A. Tiripicchio and M.T. Camellini, 1987. Reactions of $\left[\mathrm{Pd}_{2}(\mu-\mathrm{dppm})_{2} \mathrm{Cl}_{2}\right]$ with electrophilic complexes of copper and gold. Synthesis of the $\mathrm{Pd}_{4}$ cluster $\left[\mathrm{Pd}_{4}(\mu-\mathrm{Cl})_{2}(\mu-\mathrm{dppm})_{4}\right](\mathrm{PF} 6)_{2} \cdot 2\left(\mathrm{CH}_{3}\right)_{2} \mathrm{CO}$. Angew. Chem. Int. Ed. Engl., 26: 768-770.

DOI: $10.1002 /$ anie. 198707681

Bremner, W.S. and M.G. Organ, 2007. Multicomponent reactions to form heterocycles by microwaveassisted continuous flow organic synthesis. J. Comb. Chem., 9: 14-16. DOI: 10.1021/cc060130p

Cablewski, T., A.F. Faux and C.R. Strauss, 1994. Development and application of a continuous microwave reactor for organic synthesis. J. Org. Chem., 59: 3408-3412. DOI: 10.1021/jo00091a033

Collins, J.M. and N.E. Leadbeater, 2007. Microwave energy: A versatile tool for the biosciences. Org. Biomol. Chem., 5: 1141-1150.

DOI: $10.1039 / \mathrm{B} 617084 \mathrm{~F}$
Colombo, M. and I. Peretto, 2008. Chemistry strategies in early drug discovery: An overview of recent trends. Drug Discovery Today, 13: 678-684.

DOI: $10.1016 /$ j.drudis.2008.03.007

Comer, E. and M.G. Organ, 2005a. A microcapillary system for simultaneous, parallel microwave-assisted synthesis. Chem. Eur. J., 11: 7223-7227. DOI: $10.1002 /$ chem. 200500820

Comer, E. and M.G. Organ, 2005b. A microreactor for microwave-assisted capillary (continuous flow) organic synthesis. J. Am. Chem. Soc., 127: 8160-8167. DOI: $10.1021 /$ ja0512069

De Mas, N., A. Gunther, M.A. Schmidt and K.F. Jensen, 2003. Microfabricated multiphase reactors for the selective direct fluorination of aromatics. Ind. Eng. Chem. Res., 42: 698-710. DOI: $10.1021 / \mathrm{ie} 020717 \mathrm{q}$

De Mas, N., A. Gunther, T. Kraus, M.A. Schmidt and K.F. Jensen, 2005. Scaled-out multilayer gas-liquid microreactor with integrated velocimetry sensors. Ind. Eng. Chem. Res., 44: 8997-9013. DOI: $10.1021 / \mathrm{ie} 050472 \mathrm{~s}$

DeWitt, S.H., 1999. Microreactors for chemical synthesis. Curr. Opin. Chem. Biol., 3: 350-356. DOI: 10.1016/S1367-5931(99)80052-0

Ehrich, H., D. Linke, K. Morgenschweis, M. Baerns and K. Jahnisch, 2002. Application of microstructured reactor technology for the photochemical chlorination of alkylaromatics. Chimia, 56: 647-653. DOI: $10.2533 / 000942902777680063$

Fick, A., 1855. Ueber diffusion. Ann. Phys. Chem., 94: 59-86. DOI: $10.1002 /$ andp. 18551700105

Fletcher, P.D.I., S.J. Haswell, E. Pombo-Villar, B.H. Warrington and P. Watts et al., 2002a. Micro reactors: Principles and applications in organic synthesis. Tetrahedron, 58: 4735-4757. DOI: $10.1016 / \mathrm{S} 0040-4020(02) 00432-5$

Fletcher., P.D.I., S.J. Haswell and X. Zhang, 2002b. Electrokinetic control of a chemical reaction in a lab-on-a-chip micro-reactor: Measurement and quantitative modelling. Lab Chip, 2: 102-112. DOI: $10.1039 / \mathrm{B} 201685 \mathrm{~K}$

Floyd, T.M., M.A. Schmidt and K.F. Jensen, 2005. Silicon Micromixers with infrared detection for studies of liquid-phase reactions. Ind. Eng. Chem. Res., 44: 2351-2358. DOI: 10.1021/ie049348j

Fredrickson, C.K. and Z.H. Fan, 2004. Macro-to-micro interfaces for microfluidic devices. Lab Chip, 4: 526-533. DOI: 10.1039/B410720A

Gabriel, C., S. Gabriel, E.H. Grant, B.S. Halstead and D.M.P. Mingos, 1998. Dielectric parameters relevant to microwave dielectric heating. Chem. Soc. Rev., 27: 213-224. DOI: 10.1039/A827213Z 
Garcia-Edigo, E., V. Spikmans, S.Y.F. Wong and B.H. Warrington, 2003. Synthesis and analysis of combinatorial libraries performed in an automated micro reactor system. Lab Chip, 3: 73-76. DOI: $10.1039 / \mathrm{B} 302381 \mathrm{H}$

Gedye, R., F. Smith, K. Westaway, H. Ali and L. Baldisera et al., 1986. The use of microwave ovens for rapid organic synthesis. Tetrahedron Lett., 27: 279-282. DOI: $10.1016 / \mathrm{S} 0040-4039(00) 83996-9$

Geyer, K., J. Codee and P.H. Seeberger, 2006. Microreactors as tools for synthetic chemists-the chemists' round-bottomed flask of the 21 st Century? Chem. Eur. J., 12: 8434-8442. DOI: $10.1002 /$ chem. 200600596

Glasnov, T.N. and C.O. Kappe, 2007. Microwave-assisted synthesis under continuous-flow conditions. Macromol. Rapid Commun., 28: 395-410. DOI: $10.1002 /$ marc. 200600665

Glasnov, T.N., D.J. Vugts, M.M. Koningstein, B. Desai and W.M.F. Fabian et al., 2006. Microwave-assisted dimroth rearrangement of thiazines to dihydropyrimidinethiones: Synthetic and mechanistic aspects QSAR Comb. Sci., 26: 509-518. DOI: 10.1002/qsar.200540210

Hajek, M., 2006. Microwave Catalysis in Organic Synthesis. In: Microwaves in Organic Synthesis, Loupy, A. (Ed.), Wiley-VCH, Weinheim, pp: 615-652.

Handique, K., D.T. Burke, C.H. Mastrangelo and M.A. Burns, 2000. Nanoliter liquid metering in microchannels using hydrophobic patterns. Anal. Chem., 72: 4100-4109. DOI: $10.1021 / \mathrm{ac} 000064 \mathrm{~s}$

Hansen, C.L., S. Classen, J.M. Berger and S.R. Quake, 2006. A microfluidic device for kinetic optimization of protein crystallization and In situ structure determination. J. Am. Chem. Soc., 128: 3142-3143. DOI: $10.1021 /$ ja0576637

Hau, W., D.W. Trau, N.J. Sucher, M. Wong and Y. Zohar, 2003. Surface-chemistry technology for microfluidics. J. Michromech. Microeng., 13: 272-278. DOI: 10.1088/0960-1317/13/2/315

He, P., S.J. Haswell and P.D. Fletcher, 2004. Microwave heating of heterogeneously catalysed Suzuki reactions in a micro reactor. Lab Chip, 4: 38-41. DOI: $10.1039 / \mathrm{B} 313057 \mathrm{~F}$

Herrero, M.A., J.M. Kremsner and C.O. Kappe, 2008. Nonthermal microwave effects revisited: $\square$ On the importance of internal temperature monitoring and agitation in microwave chemistry. J. Org. Chem., 73: 36-47. DOI: 10.1021/jo7022697
Hu, S.W., X. Ren, M. Bachman, C.E. Sims and G.P. Li, 2002. Surface modification of poly(dimethylsiloxane) microfluidic devices by ultraviolet polymer grafting. Anal. Chem., 74: 4117-4123. DOI: $10.1021 / \mathrm{ac} 025700 \mathrm{w}$

Hunter, R.J., 1981. Zeta Potential in Colloid Science. 1st Edn., Academic Press, London.

Jachuck, R.J.J., D.K. Selvaraj and R.S. Varma, 2006. Process intensification: Oxidation of benzyl alcohol using a continuous isothermal reactor under microwave irradiation. Green Chem., 8: 29-33. DOI: $10.1039 / \mathrm{B} 512732 \mathrm{G}$

Jacob, J., L.H.L. Chia and F.Y.C. Boey, 1995. Thermal and non-thermal interaction of microwave radiation with materials. J. Mater. Sci., 30: 5321-5327. DOI: 10.1007/BF00351541

Jahnisch, K., M. Baerns, V. Hessel, W. Ehrfeld and V. Haverkamp et al., 2000. Direct fluorination of toluene using elemental fluorine in gas/liquid microreactors. J. Fluorine Chem., 105: 117-128. DOI: 10.1016/S0022-1139(00)00300-6

Jahnisch, K., V. Hessel, H. Lçwe and M. Baerns, 2004. Chemie in Mikrostrukturreaktoren. Angew. Chem., 116: 410-451. DOI: 10.1002/ange.200300577

Jas, G. and A. Kirschning, 2003. Continuous flow techniques in organic synthesis. Chem. Eur. J., 9: 5708-5723. DOI: 10.1002/chem. 200305212

Jensen, K.F., 2001. Microreaction engineering-is small better? Chem. Eng. Sci., 56: 293-303. DOI: 10.1016/S0009-2509(00)00230-X

Kaiser, N.F.K., U. Bremberg, M. Larhed, C. Moberg and A. Hallberg, 2000. Fast, convenient and efficient molybdenum-catalyzed asymmetric allylic alkylation under noninert conditions: an example of microwave-promoted fast chemistry. Angew. Chem. Int. Ed., 39: 3595-3598. DOI: 10.1002/15213773(20001016)39:20<3595::AIDANIE3595>3.0.CO;2-S

Kappe, C.O., 2004. Controlled microwave heating in modern organic synthesis. Angew. Chem. Int. Ed., 43: 6250-6284. DOI: 10.1002/anie. 200400655

Kappe, C.O., D. Dallinger and S.S. Murphree, 2009. Practical Microwave Synthesis for Organic Chemists. 1st Edn., Wiley-VCH, Weinheim, ISBN-10: 3527320970, pp: 310.

Kawaguchi, T., H. Miyata, K. Ataka, K. Mae and J. Yoshida, 2005. Room-temperature swern oxidations by using a microscale flow system. Angew. Chem., 44: 2413-2416. DOI: 10.1002/anie.200462466

Kikutani, Y., A. Hibara, K. Uchiyama, H. Hisamoto and M. Tokeshi et al., 2002. Pile-up glass microreactor. Lab Chip, 2: 193-196. DOI: $10.1039 / \mathrm{B} 208383 \mathrm{~N}$ 
Kirschning, A., W. Solodenko and K. Mennecke, 2006. Combining enabling techniques in organic synthesis: Continuous flow processes with heterogenized catalysts. Chem. Eur. J., 12: 5972-5990. DOI: $10.1002 /$ chem. 200600236

Knitter, R., D. Gohring, P. Risthaus and J. Hausselt, 2001. Microfabrication of ceramic microreactors. Microsys. Technol., 7: 85-90.

DOI: $10.1007 / \mathrm{s} 005420100107$

Kobayashi, J., Y. Mori, K. Okamoto, R. Akiyama and M. Ueno et al., 2004. A microfluidic device for conducting gas-liquid-solid hydrogenation reactions. Science, 304: 1305-1308.

DOI: $10.1126 /$ science. 1096956

Kremsner, J.M., A. Stadler and C.O. Kappe, 2006. The scale-up of microwave-assisted organic synthesis. Top. Curr. Chem., 266: 233-278. DOI: $10.1007 / 128 \quad 048$

Kuhnert, N., 2002. Mikrowellen-unterstützte reaktionen in der organischen chemie-gibt es einen nichtthermischen mikrowelleneffekt? Angew. Chem., 114: 1943-1946. DOI: 10.1002/15213757(20020603)114:11<1943::AIDANGE1943>3.0.CO;2-P

Kunz, U., A. Kirschning, H.L. Wen, W. Solodenko and R. Cecilia et al., 2005. Monolithic polymer/carrier materials: Versatile composites for fine chemical synthesis. Catal. Today, 105: 318-324.

DOI: $10.1016 /$ j.cattod.2005.06.046

Lagally, E. and R.A. Mathies, 2004. Integrated genetic analysis microsystems. J. Phys. D: Appl. Phys., 37: 245-245. DOI: 10.1088/0022-3727/37/23/R01

Langa, F., P. De la Cruz, A. De la Hoz, A. Diaz-Ortiz and E. Diez-Barra, 1997. Microwave irradiation: more than just a method for accelerating reactions. Contemp. Org. Synth., 4: 373-386. DOI: 10.1039/CO9970400373

Larhed, M. and A. Hallberg, 2001. Microwave-assisted high-speed chemistry: A new technique in drug discovery. Drug Discovery Today, 6: 406-416. DOI: $10.1016 / \mathrm{S} 1359-6446(01) 01735-4$

Larhed, M., C. Moberg and A. Hallberg, 2002. Microwave-accelerated homogeneous catalysis in organic chemistry. Acc. Chem. Res., 35: 717-727. DOI: $10.1021 / \operatorname{ar} 010074 \mathrm{v}$

Laurent, R., A. Laporterie, J. Dubac, J. Berlan and S. Lefeuvre et al., 1995. Specific activation by microwaves: myth or reality? J. Org. Chem., 57: 7099-7102. DOI: 10.1021/jo00052a022

Lee, J.N., C. Park and G.M. Whitesides, 2003. Solvent Compatibility of poly(dimethylsiloxane)-based microfluidic devices. Anal. Chem., 75: 6544-6554. DOI: $10.1021 / \mathrm{ac} 0346712$
Lewis, D.A., J.D. Summers, T.C. Ward, J.E. McGrath, 1992. Accelerated imidization reactions using microwave radiation. J. Polymer Sci., 30: 1647-1653. DOI: 10.1002/pola.1992.080300817

Lobbecke, S., W. Ferstl, S. Pani and T. Turcke, 2005. Concepts for modularization and automation of microreaction technology. Chem. Eng. Tech., 28: 484-493. DOI: 10.1002/ceat.200500005

Loones, K.T.J., B.U.W. Maes, G. Rombouts, S. Hostyn and G. Diels, 2005. Microwave-assisted organic synthesis: Scale-up of palladium-catalyzed aminations using single-mode and multi-mode microwave equipment. Tetrahedron, 61: 10338-10348. DOI: $10.1016 /$ j.tet.2005.07.105

Loupy, A., 2002. Microwaves in organic synthesis. Weinheim.

Loupy, A., F. Maurel and A. Sabatie-Gogova, 2004. Improvements in Diels-Alder cycloadditions with some acetylenic compounds under solvent-free microwave-assisted conditions: Experimental results and theoretical approaches. Tetrahedron, 60: 1683-1691. DOI: 10.1016/j.tet.2003.11.042

Madou, M.J., 2002. Fundamentals of Microfabrication: The Science of Miniaturization. 1st Edn., CRC Press, Boca Raton, ISBN-10: 0849308267, pp: 752.

Mingos, D.M.P. and D.R. Baghurst, 1991. Tilden Lecture. Applications of microwave dielectric heating effects to synthetic problems in chemistry. Chem. Soc. Rev., 20: 1-47.

DOI: 10.1039/CS9912000001

Mingos, D.M.P. and D.R. Baghurst, 1997. Applications of Microwave Dielectric Heating Effects to Synthetic Problems in Chemistry. In: MicrowaveEnhanced Chemistry, Kingston, H.M. and S.J. Haswell (Eds.), American Chemical Society, ISBN-10: 0841233756, pp: 4-7.

Mingos, D.M.P., 2005. Microwave Assisted Organic Synthesis. 1st Edn., Blackwell Publishing, Boca Raton.

Nuchter, M., B. Ondruschka, W. Bonrath and A. Gum, 2004. Microwave assisted synthesis-a critical technology overview. Green Chem., 6: 128-141. DOI: $10.1039 / \mathrm{B} 310502 \mathrm{D}$

Panke, G., T. Schwalbe, W. Stirner, S. TaghaviMoghadam and G. Wille, 2003. A practical approach of continuous processing to high energetic nitration reactions in microreactors. Synthesis, 18: 2827-2830. DOI: $10.1055 / \mathrm{s}-2003-42491$

Pennemann, H., P. Watts, S.J. Haswell and V. Hessel, 2004. Benchmarking of microreactor applications. Org. Process Res. Dev., 8: 422-439.

DOI: $10.1021 /$ op0341770 
Pereux, L. and A. Loupy, 2001. A tentative rationalization of microwave effects in organic synthesis according to the reaction medium and mechanistic considerations. Tetrahedron, 57: 9199-9223. DOI: 10.1016/S0040-4020(01)00905-X

Ratner, D.M., E.R. Murphy, M. Jhunjhunwala, D.F. Snyder and K.F. Jensen et al., 2005. Microreactor-based reaction optimization in organic chemistry-glycosylation as a challenge. Chem. Commun., 5: 578-580.

DOI: $10.1039 / \mathrm{B} 414503 \mathrm{H}$

Saaby, S., K.R. Knudsen, M. Ladlow and S.V. Ley, 2005. The use of a continuous flow-reactor employing a mixed hydrogen-liquid flow stream for the efficient reduction of imines to amines. Chem. Commun., 23: 2909-2911. DOI: $10.1039 / \mathrm{B} 504854 \mathrm{~K}$

Seeberger, P.H., K. Geyer and J.D.C. Codee, 2007. Microreactors as Tools in the Hands of Synthetic Chemists. In: New Avenues to Efficient Chemical Synthesis, Seeberger, P.H. and T. Blume (Eds.), Springer, Berlin, pp: 1-19.

Shore, G. and M.G. Organ, 2008b. Diels-Alder cycloadditions by Microwave-Assisted, Continuous flow Organic Synthesis (MACOS): The role of metal films in the flow tube. Chem. Commun. DOI: $10.1039 / \mathrm{B} 715709 \mathrm{~F}$

Shore, G. and M.G. Organ, 2010. Panning for gold in a hot flowing stream. Gold Bull., 43: 105-113. DOI: $10.1007 / \mathrm{BF} 03214975$

Shore, G., 2011. Metals in microwave: Chemistry in flow at the "speed of lightning". VDM.

Shore, G., C.J. Li and M.G. Organ, 2010. Propargyl Amine synthesis catalysed by gold and copper thin films by using Microwave-Assisted Continuous-flow Organic Synthesis (MACOS). Chem. Eur. J., 16: 126-133.

DOI: $10.1002 /$ chem.200902396

Shore, G., M. Tsimmerman and M.G. Organ, 2009. Gold film-catalysed benzannulation by MicrowaveAssisted, Continuous Flow Organic Synthesis (MACOS). Beilstein J. Org. Chem., 5: 35-35. DOI: $10.3762 /$ bjoc. 5.35

Shore, G., S. Morin and M.G. Organ, 2006. Catalysis in capillaries by Pd thin films using Microwave-Assisted Continuous-Flow Organic Synthesis (MACOS). Angew. Chem., 45: 2761-2766. DOI: $10.1002 /$ anie. 200503600

Skelton, V., G.M. Greenway, S.J. Haswell, P. Styring and D.O. Morgan et al., 2001. The preparation of a series of nitrostilbene ester compounds using micro reactor technology. Analyst, 126: 7-10. DOI: $10.1039 / \mathrm{B} 006728 \mathrm{H}$
Snyder, D.A., C. Noti, P.H. Seeberger, F. Schael and T. Bieber et al., 2005. Modular microreaction systems for homogeneously and heterogeneously catalyzed chemical synthesis. Chim. Acta, 88: 1-9. DOI: $10.1002 /$ hlca.200490304

Solodenko, W., H. Wen, S. Leue, F. Stuhlmann and G. Sourkouni-Argirusi et al., 2004. Development of a continuous-flow system for catalysis with palladium(0) particles Eur. J. Org. Chem., 17: 3601-3610. DOI: 10.1002/ejoc.200400194

Stuerga, D. and M. Lallemant, 1994. An original way to select and control hydrodynamic instabilities: microwave heating.: Part III: Linear stability analysis. J. Microw. Power Electromag. Energy, 29: 3-18. DOI: 10.1080/08327823.1994.11688227

Stuerga, D. P. Gaillard and M. Lallemant, 1996. Microwave heating as a new way to induce localized enhancements of reaction rate. Nonisothermal and heterogeneous kinetics. Tetrahedron, 52: 5505-5510. DOI: 10.1016/0040-4020(96)00241-4

Taghavi-Moghadam, S., A. Kleemann and S. Overbeck, 2000. World microtechnologies congress. MICROtech, Berlin.

Thayer, A.M., 2005. Researchers find that processes run in microreactors open doors to more efficient and novel chemistry useful for fine chemicals and intermediates. Chem. Eng. News, 83: 43-52. DOI: 10.1021/cen-v083n022.p043

Timmel, C.R. and P.J. Hore, 1996. Oscillating magnetic field effects on the yields of radical pair reactions. Chem. Phys. Lett., 257: 401-408. DOI: 10.1016/0009-2614(96)00466-6

Tsuji, M., M. Hashimoto, Y. Nishizawa, M. Kubokawa and T. Tsuji, 2005. Microwave-assisted synthesis of metallic nanostructures in solution. Chem. Eur. J., 11: 440-452. DOI: 10.1002/chem.200400417

Vanier, G.S., 2007. Simple and efficient microwaveassisted hydrogenation reactions at -moderate temperature and pressure. Synlett. DOI: $10.1055 / \mathrm{s}-2006-958428$

Wada, Y., M.A. Schmidt and K.F. Jensen, 2006. Flow distribution and ozonolysis in gas-liquid multichannel microreactors. Ind. Eng. Chem. Res., 45: 8036-8042. DOI: 10.1021/ie060893p

Wang, B., Q. Zhao, F. Wang and C. Gao, 2006. Biologically driven assembly of polyelectrolyte microcapsule patterns to fabricate microreactor arrays. Angew. Chem. Int. Ed., 45: 1560-1563. DOI: 10.1002 /anie.200502822

Watts, P. and S.J. Haswell, 2005. The application of micro reactors for organic synthesis. Chem. Soc. Rev., 34: 235-246. DOI: 10.1039/B313866F 
Westaway, K.C. and R. Gedye, 1995. The question of specific activation of organic reactions by microwaves. J. Microwave Power, 30: 219-230. DOI: $10.1080 / 08327823.1995 .11688280$

Wiles, C., P. Watts, S.J. Haswell and E. Pombo-Villar, 2001a. The aldol reaction of silyl enol ethers within a micro reactor. Lab Chip, 1: 100-101. DOI: $10.1039 / \mathrm{B} 107861 \mathrm{E}$

Wiles, C., P. Watts, S.J. Haswell, E. Pombo-Villar and P. Styring, 2001b. The synthesis of peptides using micro reactors. Chem. Commun. DOI: $10.1039 / \mathrm{B} 102125 \mathrm{G}$

Wiles, C., P. Watts, S.J. Haswell and E. Pombo-Villar, 2002a. Solution phase synthesis of $\beta$-peptides using micro reactors. Tetrahedron, 58: 5427-5439. DOI: $10.1016 / \mathrm{S} 0040-4020(02) 00513-6$
Wilson, N.S., C.R. Sarko and G. Roth, 2004. Development and applications of a practical continuous flow microwave cell. Org. Process. Res. Dev., 8: 535-538. DOI: 10.1021/op034181b

Wong-Hawkes, S.Y.F., J.C. Matteo, B.H. Warrington and J.D. White, 2007. Microreactors as New Tools for Drug Discovery and Development. In: New Avenues to Efficient Chemical Synthesis, Seeberger, P.H. and T. Blume (Eds.), Springer, Berlin, pp: 39-55.

Zhang, X., C. Wiles, S.L. Painter, P. Watts and S.J. Haswell, 2006. Microreactors as tools for chemical research. Chim. Oggi, 24: 43-45.

Zhang, X., D.O. Hayward and D.M.P. Mingos, 2003a. Effects of microwave dielectric heating on heterogeneous catalysis. Catal. Lett., 88: 33-38. DOI: $10.1023 / \mathrm{A}: 1023530715368$

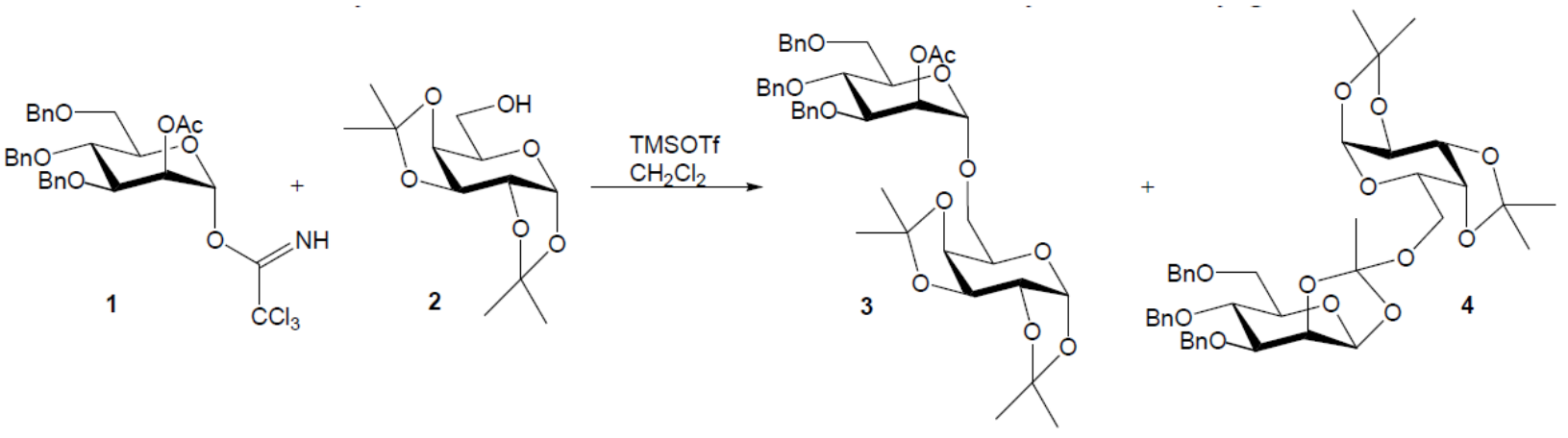

Scheme 1<smiles>C=CC(=O)OCC</smiles>

Scheme 2<smiles>Cc1ccc(F)c(F)c1</smiles>

Scheme 3 

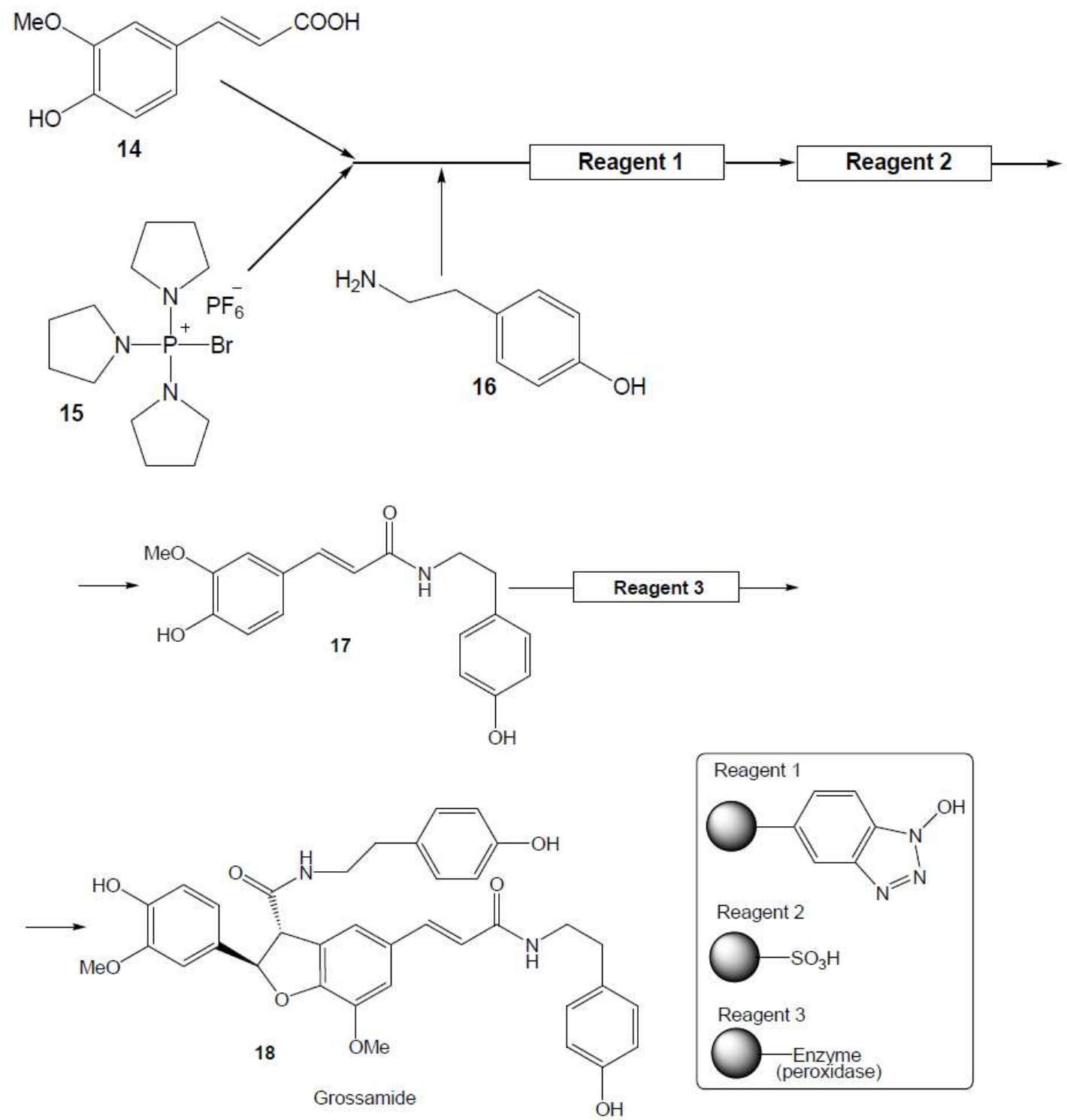

Scheme 4<smiles>C(/C=C/c1ccccc1)=C\c1ccccc1</smiles>

19
$\underset{\mathrm{Pd} / \mathrm{C}, \mathrm{H}_{2} \text { (4 bar), EtOAc }}{\stackrel{\mathrm{MW} \text { or conventional }}{\longrightarrow}}$ heating, $80^{\circ} \mathrm{C}, 5 \mathrm{~min}$<smiles>c1ccc(CCCCCc2ccccc2)cc1</smiles>

MW heating: > $99 \%$ conversion Conventional heating: $55 \%$ conversion

Scheme 5

$$
\begin{aligned}
& \text { MW or conventional } \\
& \mathrm{TiO}_{2}+3 \mathrm{C} \underset{\text { heating }}{1300-1550{ }^{\circ} \mathrm{C}} \mathrm{TiC}+2 \mathrm{CO}
\end{aligned}
$$

Scheme 6 


\section{a)}<smiles>CCOC(=O)C1=CC=CCC1</smiles>

23<smiles>[C+]1CCCCC1</smiles>

24

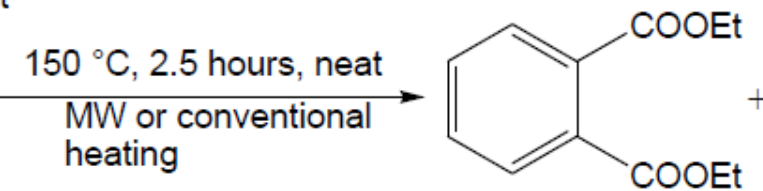

25<smiles>CCOC(=O)c1cccc(C(=O)OCC)c1</smiles>

26

No development of charges in transition state intermediate

b)

MW heating: $37 \%$ yield $(52: 48)$

Conv. heating: $36 \%$ yield $(53: 47)$<smiles>CC(=O)c1cccoc1=O</smiles>

\section{$150^{\circ} \mathrm{C}, 3$ hours, neat \\ MW or conventional heating}

Development of charges in transition state intermediate<smiles>CC(=O)c1ccccc1-c1ccccc1</smiles>

MW heating: $64 \%$ yield Conv. heating: $19 \%$ yield

Scheme 7<smiles>[R]C(=C)Br</smiles>

1.2 Equiv

45a $(R=E t)$

$45 b(R=M e)$

45c $(\mathrm{R}=\mathrm{Ph})$<smiles>Nc1ccccc1Br</smiles>

1.0 Equiv

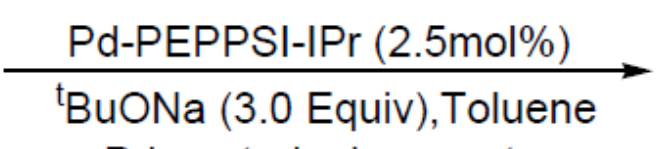
Pd-coated microreactor<smiles>[R]c1cc2ccccc2[nH]1</smiles>

$47 a(R=E t)$

$47 b(R=M e)$

47c $(R=P h)$

Scheme 8<smiles>[R]C#Cc1[X]cccc1C=O</smiles>

48

1.0 Equiv

$\mathrm{X}=\mathrm{CH}, \mathrm{N}$

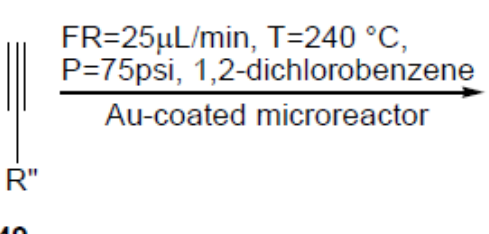

49

3.0 Equiv<smiles>[R]C(=O)c1c([R7])ccc2cccnc12</smiles>

50<smiles>[R]C(=O)c1cc([R])cc2ccccc12</smiles>

51

Scheme 9 
<smiles></smiles>

52<smiles>[R]N[R]</smiles>

53

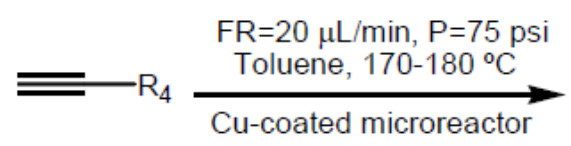

54<smiles>[R]C#CC(c1ccccc1)N([R])[R]</smiles>

55

1 Equiv

1.2 Equiv

1.5 Equiv

Scheme 10 